\title{
Crioconservación seminal en peces de agua dulce: aspectos biotecnológicos, celulares y bioquímicos
}

\section{Seminal Cryopreservation in Freshwater Fish: Biotechnological, Cellular and Biochemical Aspects}

\author{
Criopreservação Seminal em Peixes de Água Doce: Aspectos \\ Biotecnológicos, Celulares e Bioquímicos
}

\author{
Víctor M. Medina-Robles ${ }^{1}$, MVZ, MSc, PhD; Astrid S. Duarte-Trujillo ${ }^{1}$, Ing. Agroindustrial; \\ Pablo E. Cruz-Casallas ${ }^{1}, M V Z$, Esp, MSc, PhD \\ 1 Grupo de Investigación sobre Reproducción y Toxicología de Organismos Acuáticos - GRITOX, Instituto de Acuicultura \\ de los Llanos - IALL, Facultad de Ciencias Agropecuarias y Recursos Naturales - FCARN, Universidad de los Llanos, \\ Villavicencio, Colombia. \\ Email:vmmedinarobles@unillanos.edu.co
}

Recibido: 01 de julio de 2020

Aceptado: 28 de agosto de 2020

\section{Resumen}

La crioconservación es una herramienta biotecnológica que en peces está orientada principalmente a la conservación criogénica de semen como estrategia de preservación del recurso genético y a su uso para la producción de alevinos con fines diferentes. Actualmente, los protocolos de crioconservación seminal en peces de agua dulce establecen una amplia variedad de procedimientos cuya efectividad se basa en aspectos ligados a la calidad seminal post-descongelación y la fertilidad, así como su relación con el desarrollo de la progenie. El efecto de la conservación del semen en nitrógeno líquido por periodos amplios de tiempo también toma importancia en ésta biotecnología. Por lo anterior, el objetivo de la presente revisión es describir aspectos biotecnológicos, celulares y bioquímicos asociados al proceso de crioconservación seminal en peces dulceacuícolas, resaltando los avances, las limitaciones y sus perspectivas.

Palabras clave: criobiología, crioconservación, espermatozoide, peces, semen

\footnotetext{
Abstract

Cryopreservation is a biotechnological tool that in fish is mainly aimed at cryogenic conservation of semen as a strategy for preserving the genetic resource and its use for the production of fingerlings with different purposes. Currently, seminal cryopreservation protocols in freshwater fish establish a wide variety of procedures whose effectiveness is based on aspects linked to seminal post-thaw quality and fertility, as well as its relationship with the development of the progeny. The effect 
of preserving semen in liquid nitrogen for extended periods of time also plays an important role in this biotechnology. Therefore, the objective of this review is to describe biotechnological, cellular and biochemical aspects associated with the seminal cryopreservation process in freshwater fish, highlighting the advances, limitations and perspectives.

Key words: cryobiology, cryopreservation, spermatozoa, fish, semen

\begin{abstract}
Resumo
A criopreservação é uma ferramenta biotecnológica que em peixes visa principalmente a conservação criogênica do sêmen como estratégia para a preservação do recurso genético e sua utilização para a produção de alevinos para diferentes fins. Atualmente, os protocolos de criopreservação seminal em peixes de água doce estabelecem uma ampla variedade de procedimentos cuja eficácia se baseia em aspectos relacionados à qualidade e fertilidade pós-descongelamento seminal, bem como sua relação com o desenvolvimento da progênie. O efeito da preservação do sêmen no nitrogênio líquido por longos períodos de tempo também desempenha um papel importante nessa biotecnologia. Portanto, o objetivo desta revisão é descrever aspectos biotecnológicos, celulares e bioquímicos associados ao processo de criopreservação seminal em peixes de água doce, destacando os avanços, limitações e perspectivas.
\end{abstract}

Palavras-chave: criobiologia, criopreservação, esperma, peixe, sêmen

\section{Introducción}

Los peces dulceacuícolas son definidos como aquellas especies que pasan toda su vida o una parte crucial de ésta en agua dulce. Suelen clasificarse de acuerdo a su tolerancia al agua salada, en dos grupos: familias de división primaria y familias de división secundaria. Las familias de división primaria son aquellas cuyos miembros son estrictamente intolerantes al agua salada, tales como Cyprinidae, Cobitidae y la mayoría de los siluriformes. Las de división secundaria son aquellas que, pese a vivir en agua dulce pueden o alguna vez pudieron tolerar el agua de mar durante un periodo corto, tales como Cottidae, Lotidae y Valenciidae. No obstante, existen especies que no se incluyen dentro de estas categorías de familias, entre ellas: a) especies diádromas, que son aquellas que migran entre el agua dulce y marina en diferentes períodos de su vida, p. ej. Anguilla anguilla, Salmo salar; b) especies subsidiarias, que son especies no diádromas, estrictamente de agua dulce de familias principalmente marinas, p. ej. Alosa agone, Salaria fluviatilis y muchos Gobiidae; c) especies esporádicas, que son aquellas al parecer indiferentes a la salinidad y que por lo general se encuentran en estuarios, p. ej. Syngnathus abaster y muchos Mugilidae; d) especies accidentales, que son aquellas especies regularmente marinas que muy esporádicamente se capturan en aguas continentales, p. ej. Citharinus linguatula (Freyhof y Brooks, 2011; Smith et al., 2014).

Pese a ocupar menos del 1\% de la superficie terrestre, los peces de agua dulce proveen cerca del $10 \%$ de la biodiversidad de especies descritas y representan alrededor de una cuarta parte de los vertebrados del mundo (Freyhof y Brooks, 2011; Smith et al., 2014).
Tan solo en América, la biodiversidad de peces dulceacuícolas es bastante alta y representa alrededor de un tercio del estimado a nivel mundial, lo que corresponde a más de cinco mil especies (Reis et al., 2016). Sin embargo, la pérdida y degradación del hábitat causada por la urbanización, la contaminación, la sobreexplotación pesquera, la sedimentación, la divergencia del agua para el riego, las represas hidroeléctricas, los cambios ambientales y el lento avance en las políticas de uso sostenible del recurso íctico, han ido disminuyendo las poblaciones de agua dulce del planeta en aproximadamente un 83\% desde el año 1970 (Reis et al., 2016; Volpedo et al., 2017; WWF, 2018. El riesgo de extinción de los peces de agua dulce es mayor que el de los organismos terrestres, ya que son más sensibles a los cambios en el hábitat (Volpedo et al., 2017). Se estima que las tasas de extinción de peces dulceacuícolas son de 112 a 855 veces más altas que las tasas de extinción natural (Tedesco et al., 2017). En América del sur, entre el 4 al 10\% de las especies de peces enfrentan algún grado de riesgo de extinción (Reis et al., 2016). Tan solo en Colombia, la segunda nación sudamericana más biodiversa en peces de agua dulce (1500 especies registradas), se reporta 81 especies con algún grado de riesgo de extinción (Mojica et al., 2012; Reis et al., 2016).

La acuicultura en Colombia, es una actividad económica que ha ido en ascenso en los últimos años, dada su mayor rentabilidad en contraste con las actividades agropecuarias tradicionales, y la disminución significativa de la pesca de captura a causa de la sobreexplotación. El sector de la acuicultura está dominado en gran medida por la piscicultura de agua dulce interior. Para 
el año 2017 se reportaron cerca de 120 mil toneladas de productos pesqueros, siendo el departamento del Huila el principal productor con un aporte de $46 \%$ de la producción, seguido del departamento del Meta con un 13\% (OCDE, 2016; FAO, 2019; ICA, 2019).

La conservación y gestión de los recursos acuáticos además de permitir el equilibrio ecosistémico, constituye uno de los senderos productivos de la Bioeconomía, transcendental para el desarrollo sostenible de Colombia (Rajasekharan, 2017). Los Bancos de Recursos Genéticos (GRB, por sus siglas en inglés), en combinación con las Tecnologías de Reproducción Asistida (ART, por sus siglas en inglés), tienen el potencial de desacelerar la pérdida de la biodiversidad y promover el desarrollo sostenible. Los GRB constan de la recolección, procesamiento, almacenamiento y uso de germoplasmas (semen, óvulos, embriones, tejidos) y otros biomateriales (productos sanguíneos, muestras de ADN) (Medina-Robles et al., 2006; Comizzoli, 2016). Los criobancos son GRB desarrollados para preservar material genético viable a bajas temperaturas y largo término, y constituyen una herramienta útil tanto para la conservación y repoblación de especies raras, amenazadas o en peligro de extinción, como para el mejoramiento de las especies comerciales que presenten baja diversidad genética. La crioconservación en nitrógeno líquido es el método más común para la preservación del material genético en los criobancos (Martínez-Páramo et al., 2017).

Las investigaciones en crioconservación, han sido llevadas a cabo en los diferentes tipos de células de los peces, tales como, espermatozoides, células somáticas, células germinales, espermatogonias, ovocitos y embriones. Sin embargo, el tipo de célula más crioconservada son los espermatozoides, ya que, además de ocupar menos espacio, debido a su pequeño tamaño, son relativamente más resistentes al enfriamiento (Martínez-Páramo et al., 2017). Según Fernández et al. (2009), el objetivo principal de la crioconservación de espermatozoides es "mantener su viabilidad y funcionalidad durante largos periodos de tiempo".

La crioconservación seminal presenta ventajas en términos productivos, estas son: i) el suministro de semen a pedido (con fines comerciales), ii) la optimización del espacio al disminuir el número de reproductores requeridos, iii) la disponibilidad de espermatozoides de buena calidad durante y fuera de la temporada de desove, iv) la sincronización de la disponibilidad de gametos de ambos sexos, v) el transporte práctico de gametos desde y hacia las fincas, vi) la disponibilidad de espermatozoides para investigación y mejora genética (Tiersch, 2008; Cabrita et al., 2010).
Sin embargo, pese a todos los beneficios que presenta la crioconservación seminal, el proceso de congelación per se produce múltiples daños celulares en la membrana plasmática, las mitocondrias y la cromatina, debido a la formación de cristales de hielo (dentro de las células y en el medio externo), al estrés osmótico y al estrés oxidativo (Watson et al., 2001). Estos daños celulares repercuten en la calidad seminal, perjudicando tanto la fertilidad como el desarrollo embrionario. Por ende, en aras de disminuir al máximo el daño crioinducido y preservar la calidad seminal, se han ido desarrollando protocolos de crioconservación especie específicos, a través de la evaluación y estandarización de los diversos factores implicados en el proceso (Martínez-Páramo et al., 2017; Medina-Robles et al., 2019).

Se han establecido protocolos de crioconservación de semen para muchas especies de peces en todo el mundo. Los estudios se han centrado en especies de alto valor comercial, entre ellos, los salmónidos, los ciprínidos y los esturiones, que son muy usados en alimentación y pesca recreativa (Martínez-Páramo et al., 2017). No obstante, hay un interés creciente en diseñar protocolos de crioconservación para especies de áreas tropicales y subtropicales (Viveiros y Godinho, 2009; Maria et al., 2015).

La eficiencia de un protocolo de crioconservación seminal se determina mediante la evaluación de la calidad post-congelación, para comprobar que efectivamente la viabilidad de los espermatozoides se haya mantenido (Cabrita et al., 2010). La utilización de gametos de alta calidad durante la fertilización es vital para lograr altas tasas de fecundación y eclosión, así como un adecuado desarrollo embrionario (Gallego et al., 2013). Las pruebas de calidad seminal más comunes son la motilidad espermática y la fertilidad (Bobe y Labbé, 2010), aunque recientemente, la integridad de ADN y de membrana han tomado importancia ya que influyen en gran medida en las otras variables (PérezCerezales et al., 2010; Martínez et al., 2012).

En consecuencia, el objetivo de la presente revisión es describir aspectos biotecnológicos, celulares y bioquímicos asociados al proceso de crioconservación seminal en peces dulceacuícolas, resaltando los avances, las limitaciones y las perspectivas de esta herramienta biotecnológica.

\section{Aspectos biotecnológicos}

Los protocolos de crioconservación son un conjunto de procedimientos con parámetros de operación establecidos, cuyo objetivo es la preservación de células viables a largo término. Por ende, son de gran impor- 
tancia en la biología de la conservación y la acuicultura (Martínez-Páramo et al., 2017). Cualquier modificación en los parámetros de operación puede cambiar la eficiencia del protocolo (Lahnsteiner et al., 2011).

El modelamiento matemático juega un papel clave en la comprensión de los procesos biofísicos detrás de la crioconservación, durante todas las fases del proceso, y permite la optimización de la eficiencia, expresada en términos de calidad seminal (Benson, 2015). El primer modelo criobiológico fundamental fue el modelo biofísico de Mazur (1963), que determina la formación de hielo intracelular en función de la velocidad de enfriamiento, la permeabilidad de la membrana y las dimensiones de la célula. Más tarde, se desarrolló el modelo bioquímico para predecir la supervivencia celular en función de las velocidades de congelación y descongelación (Mazur et al., 1972). La combinación de estos dos modelos creó el prototipo termodinámico de optimización de las velocidades de congelación y descongelación en función del transporte de materia y energía (Woelders et al., 2004). Un desarrollo relativamente más reciente en el modelado criobiológico es el modelado de procesos en función del equilibrio de crioprotectores (Benson, 2015).

En la tabla 1, se reportan diferentes aspectos asociados a los protocolos de crioconservación de espermatozoides en algunas especies de peces dulceacuícolas durante los últimos cinco años.

\section{Procesamiento de la muestra}

Para proteger al espermatozoide de múltiples daños criogénicos se han desarrollado diversos diluyentes específicos para cada protocolo y especie, los cuales ofrecen un medio adecuado para la preservación de la viabilidad celular. Durante la dilución, el espermatozoide regula su tamaño conforme a la concentración de soluto en el diluyente, por lo que puede sufrir daño celular debido a la difusión de agua y de crioprotectores a través de la membrana celular (Fernández et al., 2009). Por ende, el diluyente debe poseer una osmolaridad adecuada que permita evitar tanto el estrés osmótico como la activación de los espermatozoides (Draper y Moens, 2009).

El semen diluido se empaca a diferentes relaciones semen: diluyente en diferentes sistemas de empaque, dependiendo del protocolo establecido y/o el diseño experimental. Independientemente del empaque escogido, es necesario contar con un sistema de identificación de muestras que puede constar de etiquetas de colores y códigos alfanuméricos o códigos de barras. Cada GRB puede definir su propio sistema de identificación, ya que actualmente no existe uno internacionalmente adoptado (Martínez-Páramo et al., 2017).

Debe procurarse que el tiempo de manipulación de las muestras sea el mínimo posible para evitar la pérdida de calidad seminal. En algunas especies como el Brycon amazonicus el tiempo máximo de manipulación puede llegar hasta los 30 minutos, contados desde su recolección (Cruz-Casallas et al., 2006a); mientras que en especies sensibles a la manipulación como el Danio rerio, el lapso de tiempo transcurrido desde la adición del diluyente hasta el inicio de la congelación no debe ser superior a 30 segundos (Draper y Moens, 2009).

\section{Diluyente}

El diluyente de crioconservación es una solución en la cual se diluye el semen previa congelación. Consta de la combinación de un extensor, un crioprotector interno y un crioprotector externo, a un $\mathrm{pH}$ y osmolaridad dada, donde cada componente del diluyente juega un papel crucial y complementario. Se recomienda que el diluyente de crioconservación tenga una osmolaridad superior que la osmolaridad del plasma seminal, ya que está reportado que bajo estas condiciones la movilidad espermática se inhibe parcial o totalmente en gran parte de las especies dulceacuícolas. La inhibición de la motilidad espermática es necesaria para preservar la calidad seminal durante el almacenamiento (Carneiro et al., 2012).

El extensor es una solución con propiedades coligativas, en el cual se disuelven los crioprotectores y el semen fresco antes de la congelación. Por lo general, el extensor consta de glucosa o cloruro de sodio a diferentes concentraciones, aunque, también se reportan formulaciones más complejas como los extensores V2E, BTS y Cortland. El agua de coco también ha sido usada con éxito, gracias a su alto contenido de minerales (Viveiros y Godinho, 2009). Según Viveiros y Godinho (2009) la solución de glucosa al 5\% es un extensor para crioconservación simple, asequible y estable que puede manipularse en granjas de peces sin la necesidad de equipos de laboratorio complejos, y que está disponible comercialmente como una solución estéril. La glucosa al 5\% se ha empleado con éxito para congelar el semen de varias especies nativas de Brasil como yamú (Brycon amazonicus), sábalo jetón (Prochilodus lineatus), cachama blanca (Piaractus mesopotamicus) y cachama roja (Piaractus brachypomus) (Viveiros y Godinho, 2009). 
La dilución del semen provoca que la concentración de los antioxidantes naturales en el plasma seminal se reduzca, lo que hace que los espermatozoides estén más expuestos al estrés oxidativo. Por ello, para reducir expresiones de estrés oxidativo como la peroxidación de lípidos, la oxidación de proteínas y la fragmentación de $A D N$, se ha evaluado en varios estudios la suplementación de los extensores con antioxidantes (vitaminas, enzimas, aminoácidos, polifenoles, entre otros). El ácido ascórbico y el tocoferol han sido de esencial importancia, ya que está comprobado que evitan la propagación de las reacciones en cadena inducidas por radicales libres (Cabrita et al., 2011). No obstante, el efecto de los antioxidantes sobre la calidad seminal depende de su concentración en el extensor, la formulación del suplemento, la especie a crioconservar y el protocolo de crioconservación (Martínez-Páramo et al., 2017); por consiguiente, algunos autores reportan mejoría en la calidad seminal post-congelación mientras que otros reportan efectos negativos. Por ejemplo, Lahnsteiner et al., (2011) evaluaron la influencia de la adición de mezclas de antioxidantes sobre la calidad seminal post-descongelación en trucha de arroyo (Salvelinus fontinalis) y trucha arcoíris (Oncorhynchus mykiss), y encontraron que la mayoría de los antioxidantes presentaron efectos negativos significativos sobre la motilidad, la velocidad, la integridad de ADN y la fertilidad, mientras que la integridad de membrana y la peroxidación lipídica no se vieron afectadas. Contrariamente, Kutluyer et al. (2014) obtuvieron incrementos significativos de la motilidad en O. mykiss empleando seis de los once antioxidantes evaluados (ácido úrico, L-metionina, superóxido dismutasa, Lcarnitina, $\alpha$-tocoferol y L-glutatión reducido), aunque las tasas de fertilidad y de eclosión no aumentaron significativamente. Öğretmen et al., (2015) también obtuvieron efectos positivos al adicionar cisteína al extensor de crioconservación de carpa común (Cyprinus carpio), logrando un aumento significativo (superior al $50 \%$ ) en la motilidad, la eclosión y la integridad de ADN en contraste con el control. En Cyprinus carpio también se han evaluado otros antioxidantes con resultados variables, tales como el hidroxitolueno butilado (BHT) (Öğretmen y Inanan, 2014a), la miel de pino (Öğretmen y Inanan, 2014b) y el propóleo (Öğretmen et al., 2014), los cuales fueron beneficiosos principalmente para la motilidad y la eclosión, en contraste con el control.

\section{Crioprotectores}

Los crioprotectores son sustancias esenciales para la supervivencia celular ya que proporcionan un entorno nutricional y osmóticamente ideal para el semen, reduciendo la tasa de congelación y las lesiones celulares mecánicas (Varela-Junior et al., 2015). Una vez el semen es mezclado con el diluyente, los crioprotectores ingresan a los espermatozoides e incrementan la concentración intracelular de solutos, promoviendo la ósmosis del agua hacia el medio extracelular. En consecuencia, los cristales de hielo se forman afuera de la célula, en donde no son nocivos. Sin embargo, en la crioconservación convencional, una alta concentración de crioprotectores internos, también conocidos como penetrantes o permeables, provoca la deshidratación excesiva de las células y daño celular irreversible debido al gradiente osmótico transmembrana (Benson, 2015). Además, algunos crioprotectores pueden inducir peroxidación lipídica (Isachenko et al., 2018) y llegar a ser tóxicos a una concentración dada (Yasui et al., 2012). En consecuencia, para que los crioprotectores sean biológicamente aceptables deben presentar baja toxicidad. Por ende, debe identificarse la concentración óptima de crioprotectores, la cual está directamente relacionada con la permeabilidad de la membrana celular (Benson, 2015). La calidad seminal postdescongelación depende en gran parte del crioprotector utilizado, de su concentración en el diluyente, su combinación con otros componentes y la velocidad de dilución (Viveiros et al., 2009).

El glicerol es el primer crioprotector interno reportado. Desde su descubrimiento se han evaluado otras sustancias químicas, siendo el dimetilsulfóxido (DMSO) y el metilglicol los más empleados (Viveiros y Godinho, 2009). El dimetilsulfóxido (DMSO) ha sido considerado el crioprotector a elección para la mayoría de los protocolos, aunque la calidad espermática alcanzada no sea siempre la mejor (Cabrita et al., 2010), ya que en algunos casos, se reportan motilidades post-descongelación de tan sólo el 5 - 10\% (Carneiro et al., 2012). Por otro lado, el metilglicol, también conocido como 2-metoxietanol o etilenglicol monometil éter, ha sido utilizado con éxito en la crioconservación de varias especies de peces dulceacuícolas (Viveiros y Godinho, 2009); aunque Shaliutina-Kolešová et al., (2015) mencionan que no es efectivo, puesto que incrementa en los espermatozoides esterlinos la sensibilidad postdescongelación a ROS. Li et al., (2010, 2013) realizaron estudios bioquímicos en carpa común (Cyprinus carpio) y revelaron que, la adición de DMSO o etilenglicol al diluyente de crioconservación no induce daño oxidativo significativo en el semen durante la dilución; en contraposición, aseveraron que los daños por estrés oxidativo son promovidos por el proceso de congelación en sí mismo, e incluyen, tanto peroxidación lipídica como cambios en la fosforilación de proteínas (en los residuos de tirosina y treonina) que conducen 
a pérdida de la función espermática. En este estudio, el efecto negativo de la crioconservación fue mayor cuando se empleó DMSO como crioprotector (Li et al., 2010, 2013). Otro estudio que reafirma el efecto negativo de la congelación sobre la motilidad espermática es el de Viveiros et al. (2009), en el cual refrigeraron durante $1 \mathrm{~h}$ semen diluido de Salminus brasiliensis y encontraron que la motilidad no cambió cuando se empleó DMSO como crioconservante aunque disminuyó levemente cuando se empleó metilglicol o glicerol; sin embargo, después de la crioconservación, la motilidad fue ralentizada hasta en un $80 \%$ con DMSO e inhibida completamente con los otros dos crioprotectores.

Los crioprotectores externos o permeables son aquellos que aunque no penetran la célula ayudan a estabilizar la membrana (Viveiros y Godinho, 2009). El crioprotector externo más evaluado ha sido la yema de huevo, obteniéndose en la mayoría de los casos parámetros de calidad más altos con su incorporación que con su omisión. La yema de huevo brinda protección a la célula debido a la presencia de lipoproteínas de baja densidad que se adhieren a la membrana plasmática y la protegen del daño mecánico. Sin embargo, la yema de huevo es poco estable y su composición es difícil de estandarizar; además, dada su viscosidad, adicionar más del 5\% al diluyente de crioconservación perjudica la movilidad de los espermatozoides y dificulta la caracterización visual de las células en el microscopio (Carneiro et al., 2012). Se han evaluado sustitutos como la ciclodextrina cargada de colesterol, que en carpa (Cyprinus carpio) han permitido valores altamente significativos de motilidad, viabilidad celular y fertilidad (Yildiz et al., 2015).

La asociación entre crioprotectores externos e internos permite potenciar la protección celular (Varela-Junior et al., 2015). La combinación óptima de crioprotectores no está generalizada y varía con respecto a la especie a crioconservar, por ello, se deben evaluar las diferentes combinaciones y concentraciones hasta encontrar la formulación que proporcione más efectos positivos sobre la calidad seminal postcongelación (Viveiros y Godinho, 2009).

\section{Sistemas de empaque}

El tipo de empaque empleado puede influir en la tasa de congelación, la tasa de descongelación, la eficiencia de almacenamiento post-congelación, la identificación de la muestra y la bioseguridad. Inclusive, entre empaques del mismo tipo existen diferencias en cuanto a su efecto sobre la calidad seminal, ya que la transferencia de calor pueden variar conforme a los materiales y procesos de fabricación empleados (Martínez-Páramo et al., 2017).

Las pajillas son el sistema de empaque más empleado para la crioconservación seminal puesto que su alta relación/superficie volumen facilita la congelación y descongelación a tasas uniformes (Maria et al., 2015). Se han evaluado pajillas de diferentes volúmenes, siendo las de $0.25 \mathrm{ml}$ y $0.5 \mathrm{ml}$ las más utilizadas (Bernáth et al., 2016; Martínez-Páramo et al., 2017) aunque las pajillas de mayor volumen (1.2 - $5.0 \mathrm{ml})$, también llamadas macrotubos, han sido probadas exitosamente (Medina-Robles et al., 2007; Ding et al., 2011; Várkonyi et al., 2019). Para el caso de peces que producen poco semen, como es el caso del pez cebra (Danio rerio), se han diseñado pajillas de doble chaqueta con una capacidad de tan sólo $0.1 \mathrm{ml}$, con un peso incorporado en cada extremo para evitar la flotabilidad sobre el agente criogénico (Grevle y Ruud, 2019). Las muestras de semen pueden congelarse individualmente en numerosas pajillas de baja capacidad o agruparse en unos pocos macrotubos, siempre y cuando las muestras correspondan a machos de la misma especie; dicha agrupación de muestras se denomina "pool" (Bernáth et al., 2016).

Se reporta también otros sistemas de empaque como los tubos capilares de vidrio y los criotubos. Los criotubos son de especial interés porque son fáciles de llenar, fáciles de rotular y permiten tener un mayor volumen disponible para la fecundación. Además, su compatibilidad con las placas de pozos facilita su procesamiento automatizado. El efecto de los criotubos sobre la calidad seminal es independiente de su volumen de empaque (Maria et al., 2015; Várkonyi et al., 2019).

\section{Congelación}

Esta etapa es el Punto Crítico de Control (PCC) del proceso, ya que debido a la formación de cristales de hielo, el choque térmico, el estrés osmótico y el estrés oxidativo, los espermatozoides sufren daño celular, que afecta principalmente la membrana plasmática, las mitocondrias y la estructura de la cromatina (Watson et al., 2001). Los cristales de hielo formados pueden ser de dos tipos: intracelulares y extracelulares. Los cristales intracelulares son generalmente nocivos ya que provocan lesiones mecánicas a las estructuras celulares, por el contrario, los cristales externos resultan inocuos. La congelación sin protección es normalmente letal, por ende, debe procurarse que el diluyente de crioconservación cuente en su composición con sustancias crioprotectoras que permitan preservar la 
vida celular o al menos atenuar el daño crioinducido (Pegg, 2015).

La respuesta celular de los espermatozoides en el transcurso de la congelación recibe el nombre de curva de congelación, y debe realizarse para cada especie (Fernández et al., 2009). La tasa de congelación para cualquier sistema hace referencia a la velocidad (expresada en unidades de temperatura/ tiempo) a la que el agua de una muestra se convierte en hielo (Maria et al., 2015), y tiene una fuerte influencia en la homeóstasis celular. Lo ideal es que durante la congelación, el agua intracelular salga al medio externo, de modo que aumente la osmolaridad en el citoplasma y el descenso crioscópico originado evite la formación de hielo intracelular (Benson, 2015). Cuando la congelación se realiza progresivamente, hay suficiente tiempo para la deshidratación celular, por lo que sólo se forma hielo extracelular (Carneiro et al., 2012). Por el contrario, cuando la congelación ocurre de manera súbita, la célula no alcanza a deshidratarse por completo y el remanente de agua intracelular se congela, provocando lesiones criogénicas (Yang et al., 2009), las cuales son responsables de la pérdida de motilidad, viabilidad y normalidad morfológica en los espermatozoides. Abed-Elmdoust et al., (2019) afirman que las altas tasas de congelación permiten preservar con éxito la creatina fosfato $(\mathrm{CrP})$ y la creatinquinasa $(\mathrm{CK})$, moléculas importantes en la regeneración del ATP post-activación. De hecho, Martínez y Pardo (2013) aseguran que "la tasa de congelación posee un efecto principal significativo sobre la movilidad total", e inclusive, este efecto es más influyente que el de la tasa de descongelación. Varios autores recomiendan para la crioconservación seminal de Characiformes, tasas de congelación en un rango comprendido entre aproximadamente $2-10{ }^{\circ} \mathrm{C} /$ min (Pegg, 2007; Martínez y Pardo, 2013; Maria et al., 2015), mientras que otros autores recomiendan que sea entre $10-50{ }^{\circ} \mathrm{C} / \mathrm{min}$ (Viveiros et al., 2009; Carneiro et al., 2012).

La congelación de las muestras se puede efectuar mediante diferentes métodos, tales como, la colocación en hielo seco, la suspensión en vapores de nitrógeno dentro de un cargador seco (Dry Shipper), la vitrificación y el enfriamiento controlado en un congelador programable. Los dos primeros son más prácticos y económicos, por lo que se prefieren para uso en campo, mientras que el último es más recomendado para investigaciones de tipo experimental (MartínezPáramo et al., 2017). Para Carneiro et al., (2012), los contenedores de carga seca (Dry Shipper) son más viables que los congeladores programables para la congelación de semen de cachama negra (Colossoma macropomum), ya que afectan menos la viabilidad y motilidad espermática.

Miller et al. (2018) han empleado un método de congelación particular, modificando el uso del hielo seco y empleándolo como molde para pellets. Para ello, los investigadores hicieron hoyos de 5 - $7 \mathrm{~mm}$ de diámetro sobre el hielo seco y depositaron alícuotas de semen diluido en cada uno de ellos. Los pellets de semen formados, fueron sumergidos en nitrógeno líquido y almacenados en crioviales dentro de un Dewar.

\section{Almacenamiento}

Durante el almacenamiento, no hay transferencia de materia ni de energía, por lo que los daños celulares post-crioconservación no se derivan del almacenamiento a bajas temperaturas sino de los procesos de congelación y descongelación del semen (Fernández et al., 2009).

Si bien es cierto que la crioconservación permite la disponibilidad de espermatozoides de calidad durante y fuera de la temporada de desove (Cabrita et al., 2010), el tiempo de almacenamiento no debe ser tan prolongado, ya que esto incrementa los costos de mantenimiento. Por otro lado, el semen crioconservado debe estar en constante rotación, para así promover la variabilidad genética de las poblaciones tanto nativas como cautivas y no debe usarse exclusivamente cuando la población está en inminente peligro de extinción debido a que, en una situación realmente crítica, la población no se salvará si las hembras no están disponibles (Martínez-Páramo et al., 2017).

Algunos autores han usado el vapor de nitrógeno para almacenar muestras a largo término, aunque en contraposición, Draper y Moens (2009) afirman que bajo estas condiciones el semen pierde viabilidad con el tiempo, por lo que recomiendan mejor el almacenamiento en nitrógeno líquido. Sin embargo, el efecto del almacenamiento de semen de especies nativas dulceacuícolas en nitrógeno líquido a largo término aún no está bien definido, siendo necesario mayores estudios al respecto para la toma de decisiones.

\section{Descongelación}

La tasa de descongelación dada por cualquier sistema hace referencia a la velocidad (en unidades de temperatura/unidades de tiempo) a la que una muestra se descongela. Su estandarización juega un papel clave en el desarrollo de los protocolos de crioconservación seminal (Maria et al., 2015), ya que se ha sugerido que las lesiones en los espermatozoides durante la crio- 
conservación convencional está relacionada principalmente con el efecto negativo de la descongelación (Isachenko et al., 2018). Cuando la tasa de descongelación es lenta, los cristales de hielo se recristalizan, se fusionan y crecen, conduciendo a un mayor daño celular; mientras que, cuando la tasa de descongelación es rápida, no hay tiempo suficiente para la recristalización, de modo que el hielo simplemente se derrite (Benson, 2015).

Martínez y Pardo (2013) evaluaron diferentes tasas de descongelación de semen y encontraron que una tasa lenta de congelación en combinación con una tasa rápida de descongelación poseen efectos significativamente mejores sobre la calidad seminal del bocachico (Prochilodus magdalenae), en contraste con una tasa rápida de congelación y una tasa lenta de descongelación. Sin embargo, encontraron que los efectos de estas interacciones sobre la motilidad seminal son nulos, en contraste con los efectos independientes (efectos principales) que son determinantes. Las condiciones de descongelación, deben ser detalladamente evaluadas ya que, en algunos casos, como el de la carpa y la perca, se reporta activación espontánea inducida por el gradiente térmico, lo que consume el ATP intracelular antes de tiempo y perjudica la capacidad de fertilización del semen (Dzyuba et al., 2010). Algunas temperaturas de descongelación y tiempos son mostradas en la Tabla 1.

\section{Solución activadora}

El semen se activa cuando entra en contacto con soluciones a dada osmolaridad, concentración de iones, $\mathrm{pH}$, temperatura $\mathrm{y} / \mathrm{o}$ tasa de dilución (Alavi et al., 2006; Cosson, 2010). Las condiciones de activación espermática difieren mucho entre peces dulceacuícolas y peces marinos, inclusive, entre especies (Martínez-Páramo et al., 2017). En general, la motilidad espermática en peces dulceacuícolas es inducida por medios hipoosmóticos en relación con el líquido seminal, aunque en algunos casos, la motilidad puede ser inducida por medios isotónicos. Es recomendable que, la osmolaridad de la solución de activación en peces dulceacuícolas sea menor que la osmolaridad del plasma seminal (Maria et al., 2010). No obstante en ciertos casos, la exposición a condiciones de osmolaridad extrema como la del agua destilada (4 mOsm) puede conducir a cambios en la morfología de los espermatozoides (Carneiro et al., 2012); por ejemplo, los espermatozoides de lucio del norte (Esox lucius L.) activados con agua destilada presentaron ampollas a lo largo del flagelo, y posteriormente, restricción del desarrollo de las ondas en la parte proximal a causa del acortamiento del flagelo que se dobló en forma de bucle, lo que condujo al decrecimiento de la duración de la motilidad (Alavi et al., 2009).

El rango óptimo de osmolaridad para la activación espermática en peces dulceacuícolas oscila por lo general entre 100 - 250 mOsm. Se reportan rangos de osmolaridad óptimos de 90 - 110 mOsm para carpa (Cyprinus carpio), 100 - 150 mOsm para perca (Perca fluviatilis), 125 - 235 mOsm para lucio europeo (Esox lucius L) y 230 mOsm para cachama negra (Colossoma macropomum) (Carneiro et al., 2012). Melo-Maciel et al., (2015) sugieren una osmolaridad óptima de 100 mOsm para Characiformes como Prochilodus brevis, Colossoma macropomum y Piaractus brachypomus.

Se han empleado varias soluciones de activación, siendo las más comunes $\mathrm{NaCl}(0.3 \%), \mathrm{NaHCO}_{3}(1 \%)$ y agua destilada (Viveiros y Godinho, 2009). Carneiro et al., (2012) evaluaron la influencia de la solución activadora en la motilidad y duración de la motilidad en semen de Colossoma macropomum, y encontraron que, no existen diferencias estadísticamente significativas entre la solución salina $(\mathrm{NaCl})$ y el bicarbonato de sodio acuoso $\left(\mathrm{NaHCO}_{3}\right)$; con ambas soluciones activadoras se alcanzaron motilidades superiores al $80 \%$, con una duración media de aproximadamente 50 segundos.

\section{Parámetros de calidad seminal}

Antes de diluir el semen y empacarlo en pajillas, es necesario evaluar la calidad espermática para determinar qué tan conveniente es crioconservarlo y qué tan factible es obtener la fertilidad esperada (Martínez-Páramo et al., 2017). Además, los parámetros de calidad indican qué tan eficiente es un protocolo (Bernáth et al., 2016), por lo que deben medirse en todos los pasos relevantes a lo largo del proceso; por ejemplo, pueden evaluarse recién se colecte el semen, después de la adición del diluyente, después de la refrigeración y después de la descongelación (Martínez-Páramo et al., 2017). El análisis clásico de calidad espermática se centra en tres parámetros principales: concentración, motilidad y morfología espermática, los cuales pueden determinarse fácilmente mediante microscopía óptica o técnicas colorimétricas (Ramalho-Santos et al., 2007). Aunque, existen también otras pruebas de calidad que permiten predecir mejor la fertilidad seminal, tales como la integridad de ADN y la integridad de membrana (Pérez-Cerezales et al., 2010). Para garantizar una mayor confiabilidad de los resultados, es necesario, evaluar varios parámetros de calidad seminal y correlacionarlos, ya que un solo parámetro no determina el éxito de la fertilización (Varela-Junior et al., 2015). Sin embargo, aunque existan diferentes paráme- 
tros para establecer la calidad seminal postdescongelación, la prueba de fertilidad siempre mostrará de forma más objetiva el éxito del proceso de crioconservación.

\section{Volumen de esperma}

Un volumen grande del semen es deseable porque facilita el manejo de los ejemplares y la manipulación de los gametos. Está reportado que inducir hormonalmente a los ejemplares incrementa el volumen de esperma. Por lo general, la hormona aplicada es la hipófisis de carpa, aunque también se han realizado experimentos con la gonadotropina coriónica humana (hCG) y la hormona liberadora de la hormona luteinizante (LHRH) (Viveiros y Godinho, 2009). Algunos volúmenes de eyaculado se relacionan en la tabla 1.

\section{Concentración espermática}

La concentración espermática indica el número de espermatozoides contenidos en un mililitro $(\mathrm{spz} / \mathrm{ml})$ o un microlitro $(\mathrm{spz} / \mu \mathrm{l})$ de semen. Está muy influenciada por la inducción hormonal, ya que en los peces inducidos la concentración espermática disminuye a raíz de un significativo aumento del líquido seminal. Por ende, existe una correlación negativa entre la concentración espermática y el volumen seminal. Por otro lado, existe una correlación positiva entre la concentración espermática y el espermatocrito, que es un indicador de densidad seminal. El espermatocrito es el porcentaje de material sólido empaquetado en el semen después de la centrifugación (Cruz-Casallas et al., 2006b; Viveiros y Godinho, 2009).

Es esencial conocer la concentración de espermatozoides para poder determinar dosis de seminación efectivas. El método más común para la medición de la concentración seminal es el método del hemocitómetro basado en microscopía óptica, que consta de un recuento celular en cámara de neubauer, luego de inmovilización con una solución fijadora. El método del hemocitómetro es sencillo y económico, sin embargo, consume mucho tiempo y presenta variabilidad debido a errores de dilución. El hemocitómetro se puede usar para calibrar espectrofotómetros, de modo que la concentración se determine con base en la absorbancia de la muestra y no por el recuento visual. Los resultados con mejor correlación entre las densidades ópticas de los espermatozoides y su recuento celular, se han obtenido a $260 \mathrm{~nm}$, que es la longitud de onda a la que el ADN absorbe la luz. El método espectrofotométrico permite una determinación más rápida de la concentración en contraste con el microscópico, ya que arroja directamente lecturas digitales o electróni- cas (Ramalho-Santos et al., 2007; Fauvel et al., 2010); además funciona con un bajo volumen de muestra, de tan sólo 1 - $2 \mu \mathrm{L}$ de semen diluido, en contraste con el método microscópico que requiere de al menos $10 \mu \mathrm{L}$ de semen, lo que resulta útil para la evaluación seminal en peces de acuario (Tan et al., 2010).

Otros métodos para medir la concentración espermática son la citometría de flujo, la microscopía de fluorescencia, los contadores Coulter y la determinación de los valores de espermatocrito. Si bien es cierto que los métodos del citómetro de flujo y de los contadores Coulter son precisos, sus costos de adquisición y mantenimiento son elevados (Fauvel et al., 2010).

Una forma más práctica de determinar la concentración es mediante el procesamiento de imágenes digitales asistido por computadora, para el cual se emplea un equipo de generación CASA llamado Analizador de Clase de Esperma (SCA, por sus siglas en inglés) (Aulesa et al., 2009). Algunos reportes de concentración espermática en peces dulceacuícolas son mostrados en la Tabla 1.

\section{Cinética espermática}

La motilidad es un indicador de la actividad metabólica de los espermatozoides (Melo-Maciel et al., 2015), cuyo comportamiento está determinado por la trayectoria de la cabeza del espermatozoide en función de las ondas desarrolladas por el flagelo en respuesta a las señales externas que regulan el axonema. Además de movilidad, el flagelo proporciona orientación, mientras que la cabeza juega un papel pasivo. Debido a la alta frecuencia del latido flagelar en peces (de hasta los $100 \mathrm{~Hz}$ ), los espermatozoides pueden llegar a alcanzar una velocidad inicial de hasta $200 \mu \mathrm{m} / \mathrm{s}$ (Boryshpolets et al., 2018). La mecánica de fluidos aplicada a nanoescala ofrece la estimación de los requisitos energéticos de los flagelos para desplazarse en el medio acuático, mediante la aplicación de la teoría de la fuerza resistiva desarrollada inicialmente por Gray y Hancock (1955). En general, la cinética espermática está relacionada con el éxito reproductivo en peces (Viveiros et al., 2010; Gallego et al., 2013), mientras que la velocidad espermática se correlaciona con la fertilidad (Viveiros et al., 2010).

En la mayoría de especies de peces, los espermatozoides no presentan motilidad mientras permanecen en el medio isosmótico del plasma seminal dentro del tracto genital (Viveiros y Godinho, 2009). La activación del semen está en función de la actividad del canal iónico de la membrana plasmática. El semen se activa cuando entra en contacto con soluciones a dada osmolaridad 
y/o concentración de iones, dependiendo de la especie. En general, la motilidad espermática en peces dulceacuícolas es inducida por medios hipoosmóticos en relación con el líquido seminal en contraste con los peces marinos que se activan en medios hiperosmóticos (Cosson, 2010); aunque en algunos casos, la motilidad puede ser inducida por medios isotónicos. Bajo este contexto, en peces dulceacuícolas es recomendable que la osmolaridad con respecto al plasma seminal sea mayor en el diluyente de crioconservación y menor en la solución de activación (Alavi et al., 2006).

Los cambios en las concentraciones de iones son clave en la hiperpolarización de la membrana (Boryshpolets et al., 2018); en particular, el aumento de $\mathrm{Ca}^{2+}$ intracelular es necesario para el inicio de la motilidad espermática en los peces (Figueroa et al., 2019), del mismo modo que el flujo de salida de $\mathrm{Na}^{+}$y $\mathrm{K}^{+}$, lo que conduce al aumento en la concentración de Adenosin Monofosfato Cíclico (cAMP), molécula encargada de la transducción de señales en la fosforilación de proteínas (Alavi et al., 2006). Yasui et al. (2012) aumentaron las concentraciones del $\mathrm{Ca}^{2+}$ y $\mathrm{Mg}^{2+}$ extracelular y obtuvieron un decrecimiento progresivo de la motilidad espermática en el pez dojo (Misgurnus anguillicaudatus), mientras que el aumento del $\mathrm{K}^{+}$extracelular no alteró la motilidad. Para el caso específico de la trucha (Salmo trutta), los esturiones (Acipenser spp.) y el pez espátula (Polyodon spathula), la concentración extracelular de $\mathrm{K}^{+}$debe ser considerablemente más baja que la concentración intracelular (Boryshpolets et al., 2018). En salmónidos, el nivel calcio libre $\left(\mathrm{Ca}^{2+}\right)$ se presenta en un rango de concentración de 30 nM para espermatozoides basales a $180 \mathrm{nM}$ para espermatozoides móviles (Alavi et al., 2006).

Después de la activación, las concentraciones de iones dentro de los espermatozoides se reequilibran y la presión osmótica se vuelve perjudicial para la integridad espermática. Además, las reservas energéticas terminan agotándose debido a que la capacidad de los espermatozoides para restaurar las reservas de ATP es insuficiente. En consecuencia, el tiempo de activación se limita a un breve intervalo (Cosson, 2010; Boryshpolets et al., 2018). El tiempo de activación o duración de la movilidad es una compensación entre la reserva energética y el proceso de daño osmótico experimentado por la célula, y está fuertemente ligado a la temperatura del medio (dentro del rango fisiológico del pez), ya que a mayor temperatura el agotamiento energético celular es más rápido. Los peces dulceacuícolas, en contraste con los peces marinos, son más susceptibles al daño osmótico, por ende su tiempo de activación es de tan sólo 0,5 - 2 min (Boryshpolets et al., 2018). Bajo este contexto, es importante que los espermatozoides permanezcan inmóviles antes y durante la crioconservación, y sólo se activen para su uso (Viveiros y Godinho, 2009).

Está comprobado que el proceso de congelación afecta notablemente la cinética espermática (Benson, 2015). Martínez y Pardo (2013) encontraron que la motilidad en Prochilodus magdalenae disminuye significativamente del $99 \%$ al $60 \%$ tras congelación lenta $\left(-2{ }^{\circ} \mathrm{C} / \mathrm{min}\right)$, mientras que cuando la congelación es rápida $\left(-28 \pm 1{ }^{\circ} \mathrm{C} / \mathrm{min}\right)$ se inhibe completamente (motilidad $=0 \%$ ). Takei et al., (2012) afirman que dicha alteración de la cinética espermática se debe cambios en los patrones de distribución de $\mathrm{Ca}^{2+}$ debido a la alteración de la fosforilación de proteínas como la proteína quinasa A (PKA) y la dineína en el axonema flagelar, producto del choque térmico y osmótico. Pese a ello, Figueroa et al., (2019) aseveran que existe escasa información sobre los efectos de la crioconservación en la concentración de $\mathrm{Ca}^{2+}$ intracelular.

La motilidad espermática puede estar influenciada por uno o varios factores, entre ellos, la inducción hormonal, la dieta, la etapa de maduración, las condiciones ambientales, el contenido de ATP, la actividad enzimática, la regulación hormonal de espermiación, la actividad secretora del conducto espermático, la contaminación en laboratorio y las características de la solución de activación (Alavi et al., 2006; Melo-Maciel et al., 2015). En especial, la motilidad post-descongelación está fuertemente influenciada por el tiempo y la temperatura de descongelación (Maria et al., 2015). La osmolaridad y el $\mathrm{pH}$ son factores directamente relacionados con la motilidad, ya que pueden inducirla o inhibirla, dependiendo del caso; por ello, tanto el diluyente de crioconservación como la solución activadora deben formularse con base en estos (Pinheiro et al., 2016). Por otro lado, se ha informado que suplementar la alimentación de los ejemplares con boro en cantidades reguladas, puede mejorar la resistencia de los espermatozoides al choque frío y conllevar a un aumento de la duración de la motilidad post-congelación (İnanan y Yilmaz, 2018).

El análisis de la motilidad en muestras frescas y sin diluir, es necesario para descartar muestras activadas prematuramente por contaminación con agua, sangre, heces u orina (Viveiros y Godinho, 2009). Del mismo modo, el análisis de motilidad post-congelación es imperioso para evaluar los efectos de la crioconservación sobre la calidad seminal (Cabrita et al., 2010).

La motilidad de los espermatozoides puede evaluarse mediante estimación subjetiva por microscopía óptica y expresarse como porcentaje de movilidad masal 


\begin{tabular}{|c|c|c|c|c|c|c|c|}
\hline 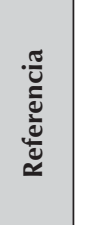 & 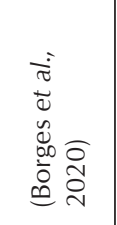 & 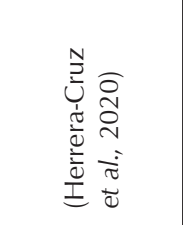 & 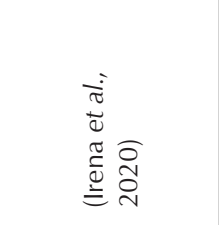 & 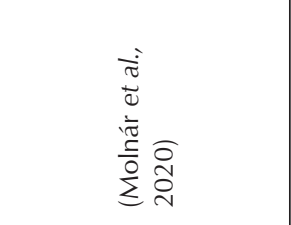 & 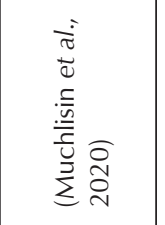 & 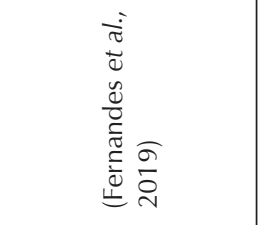 & 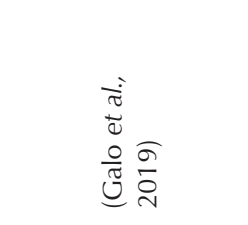 \\
\hline 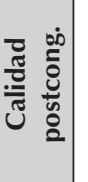 & 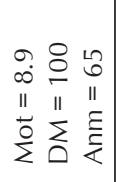 & 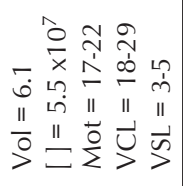 & 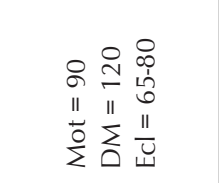 & 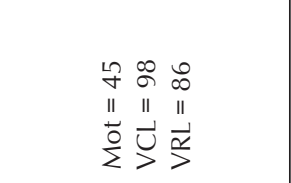 & 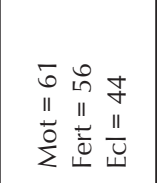 & 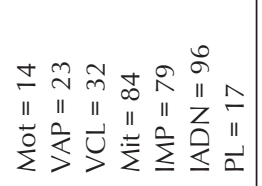 & 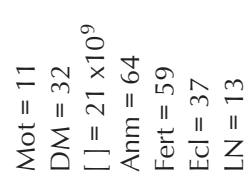 \\
\hline ชิ & $\begin{array}{l}\bar{U} \\
\dot{u} \\
\dot{q}\end{array}$ & نे & $\begin{array}{l}\bar{u} \\
\dot{q} \\
\dot{q}\end{array}$ & Ù & 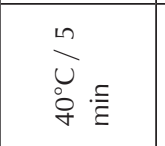 & $\frac{\mathscr{z}}{\mathrm{z}}$ & 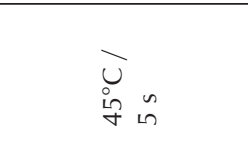 \\
\hline 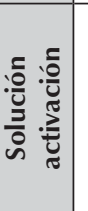 & 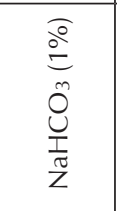 & 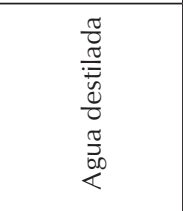 & 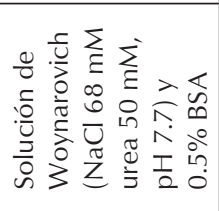 & 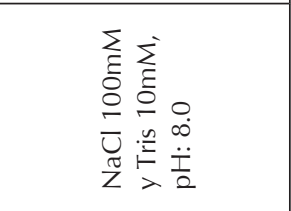 & 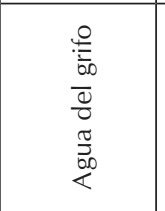 & 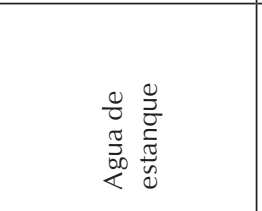 & 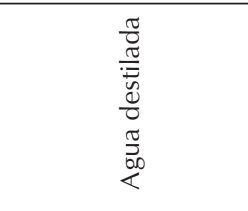 \\
\hline 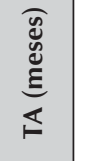 & 6 & $\bar{v}$ & $\bar{v}$ & $\bar{v}$ & $\bar{v}$ & $\stackrel{\text { ?? }}{\longrightarrow}$ & $\bar{v}$ \\
\hline 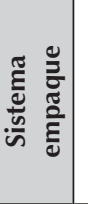 & 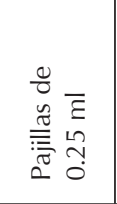 & 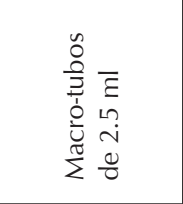 & 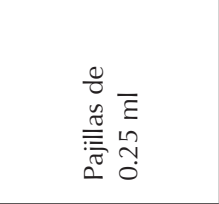 & 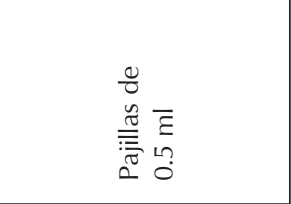 & 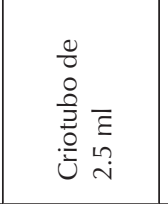 & 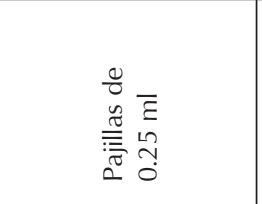 & 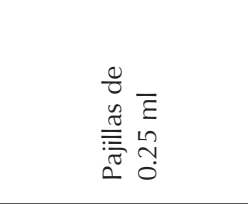 \\
\hline 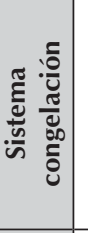 & 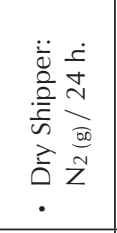 & 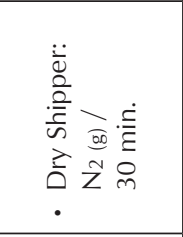 & 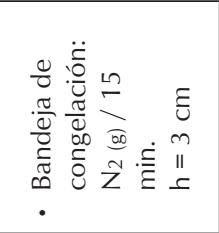 & 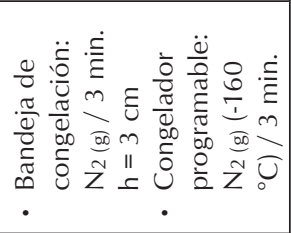 & 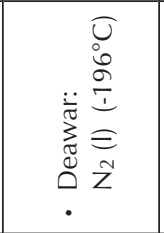 & 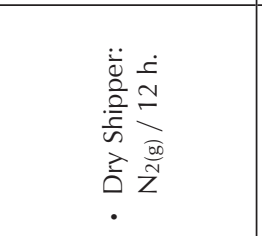 & 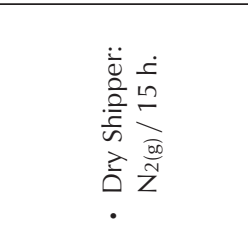 \\
\hline 竎 & 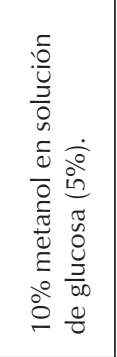 & 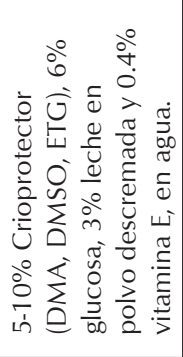 & 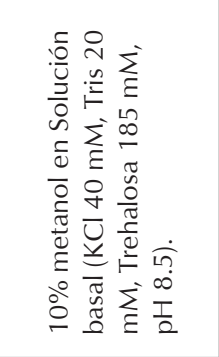 & 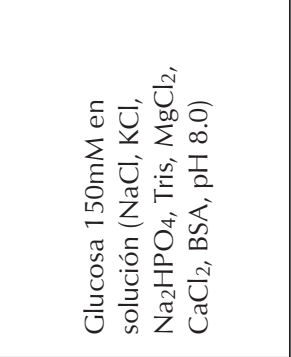 & 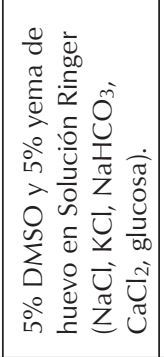 & 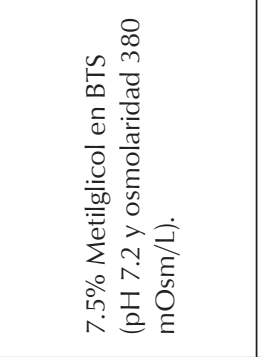 & 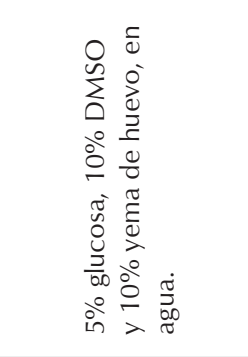 \\
\hline$\underset{\varkappa}{z}$ & $\stackrel{\mathscr{T}}{\longrightarrow}$ & $\stackrel{m}{=}$ & $\stackrel{\mathscr{P}}{-}$ & $\stackrel{m}{=}$ & $\stackrel{\stackrel{\Upsilon}{-}}{.}$ & $\stackrel{\mathscr{P}}{\mathscr{P}}$ & $\stackrel{m}{=}$ \\
\hline 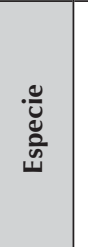 & 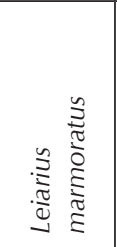 & 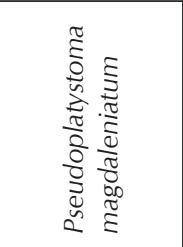 & 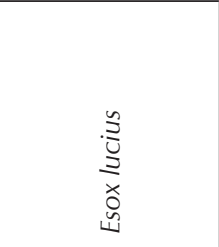 & 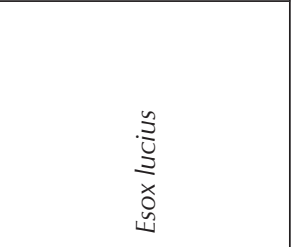 & 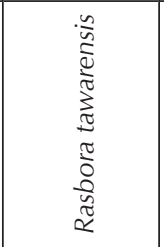 & 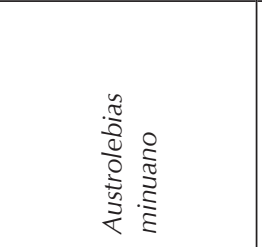 & 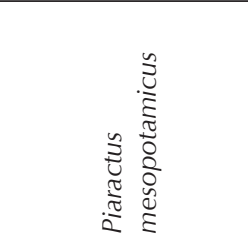 \\
\hline
\end{tabular}




\begin{tabular}{|c|c|c|c|c|c|c|c|}
\hline 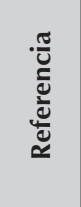 & 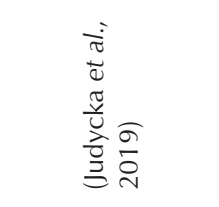 & 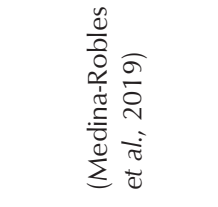 & 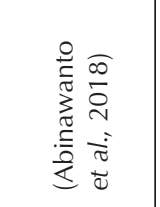 & 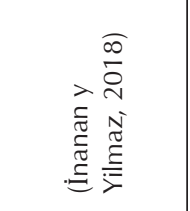 & 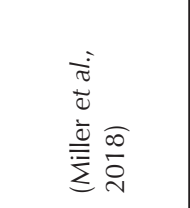 & 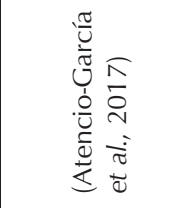 & 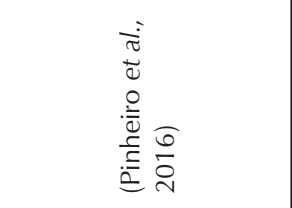 \\
\hline 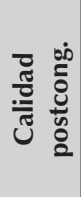 & 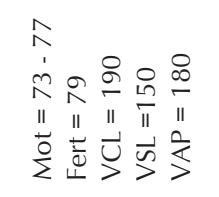 & 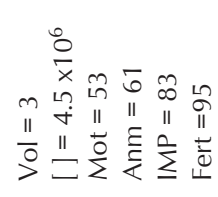 & 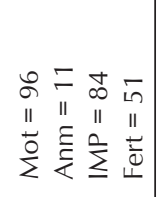 & 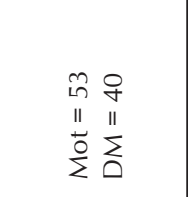 & 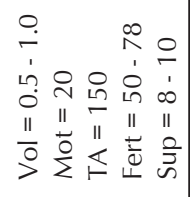 & 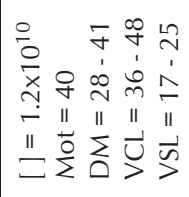 & 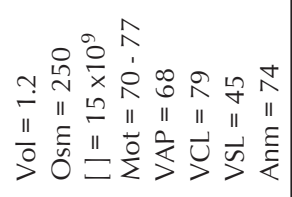 \\
\hline ช & $\begin{array}{l}\bar{U} \\
\circ \\
\dot{q}\end{array}$ & $\begin{array}{l}\bar{U} \\
\grave{L} \\
\dot{m}\end{array}$ & $\begin{array}{l}\bar{u} n \\
\dot{a} \\
\dot{q}\end{array}$ & $\begin{array}{l}\bar{U} \\
\stackrel{0}{0}\end{array}$ & 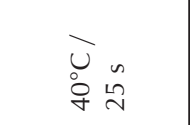 & ì & ì \\
\hline 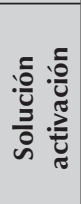 & 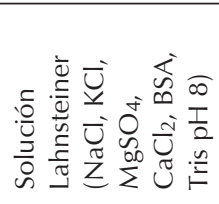 & 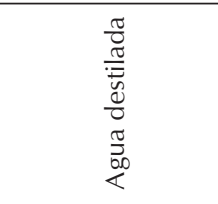 & 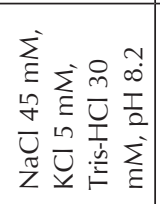 & 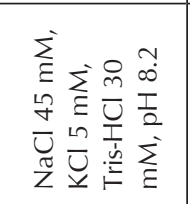 & 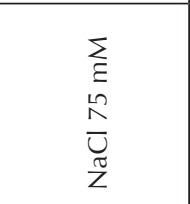 & 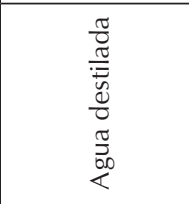 & 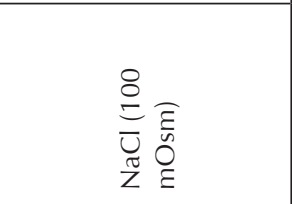 \\
\hline 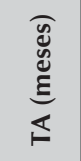 & $\frac{\mathscr{c}}{Z}$ & $\infty$ & $\bar{v}$ & $\bar{v}$ & $\stackrel{m}{m}$ & $n$ & $\bar{v}$ \\
\hline 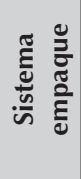 & 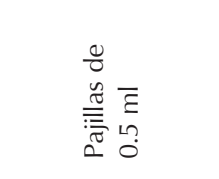 & 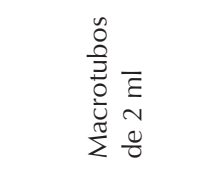 & 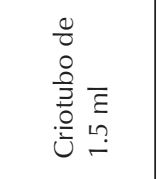 & 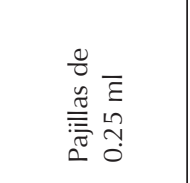 & 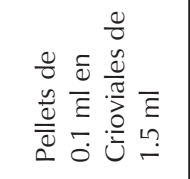 & 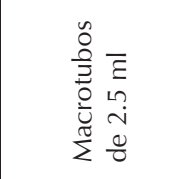 & 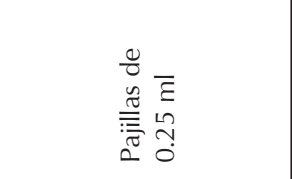 \\
\hline 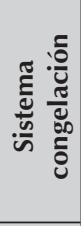 & 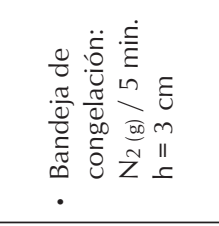 & 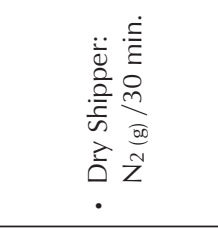 & 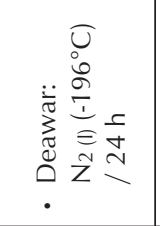 & 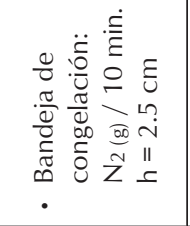 & 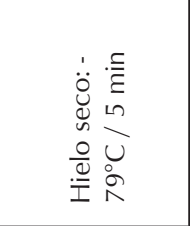 & 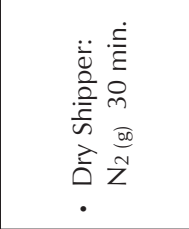 & 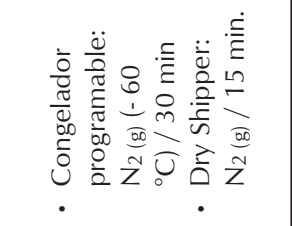 \\
\hline 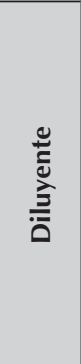 & 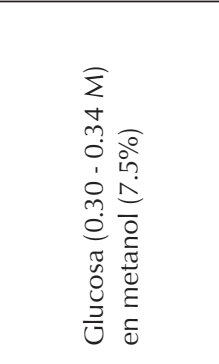 & 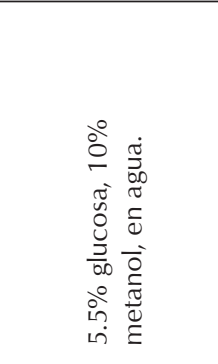 & 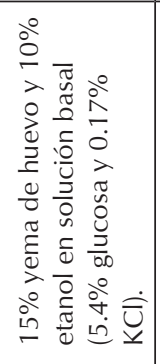 & 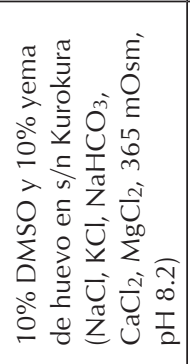 & 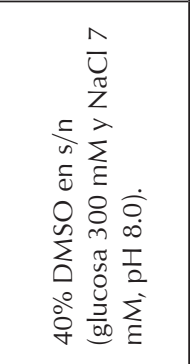 & 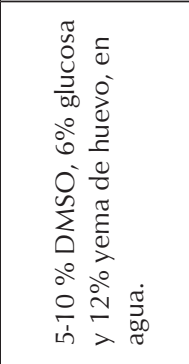 & 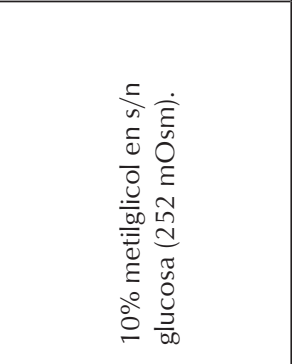 \\
\hline$\underset{x}{z}$ & $\stackrel{\sim}{z}$ & $\stackrel{+}{+}$ & $\stackrel{\varphi}{=}$ & $\stackrel{\mathscr{P}}{=}$ & $\stackrel{+}{+}$ & $\stackrel{m}{=}$ & بِ \\
\hline 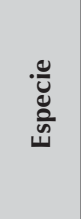 & 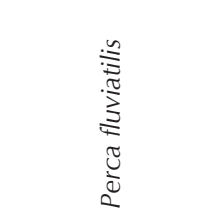 & 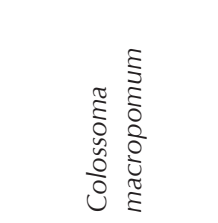 & 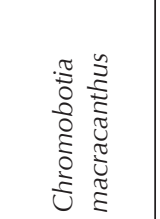 & 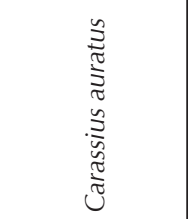 & 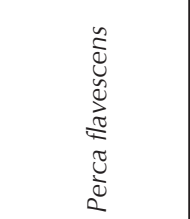 & 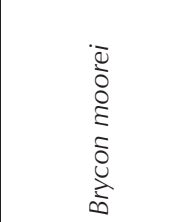 & 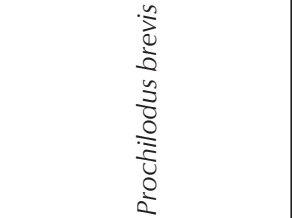 \\
\hline
\end{tabular}




\begin{tabular}{|c|c|c|c|c|c|c|c|c|}
\hline 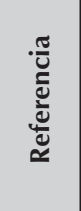 & 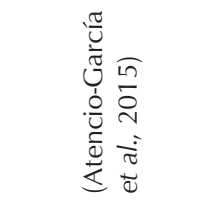 & 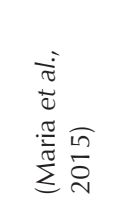 & 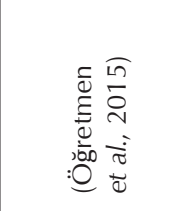 & 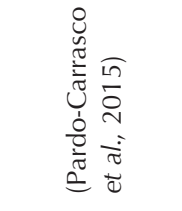 & 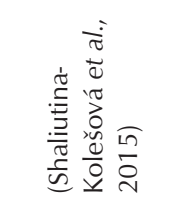 & 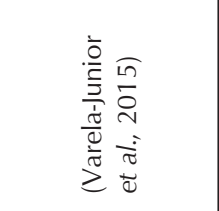 & 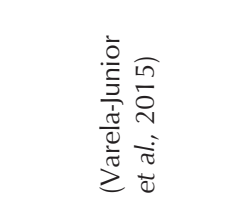 & 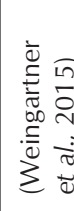 \\
\hline 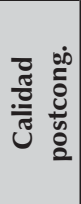 & 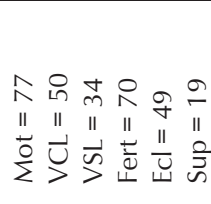 & 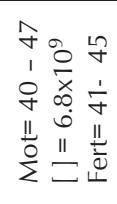 & 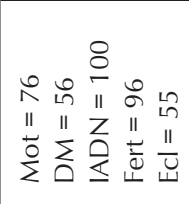 & 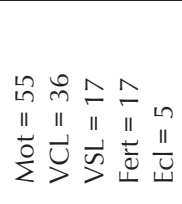 & 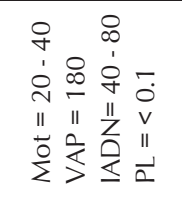 & 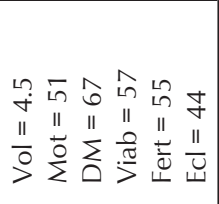 & 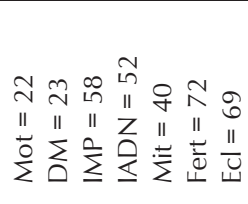 & 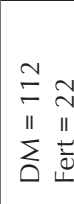 \\
\hline ช & 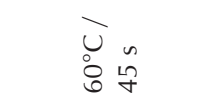 & $\begin{array}{l}u \\
\text { Oें } \\
\dot{B}\end{array}$ & 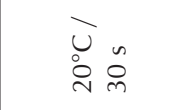 & 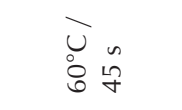 & $\begin{array}{l}\bar{u} \\
0 \\
\dot{q} \\
\text { in }\end{array}$ & 广̀ & $\begin{array}{l}\bar{u} \\
\text { in } \\
\text { in }\end{array}$ & 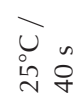 \\
\hline 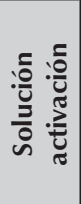 & 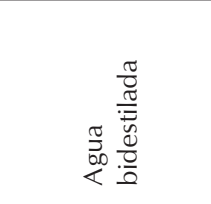 & 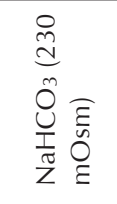 & 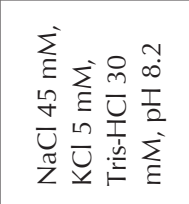 & 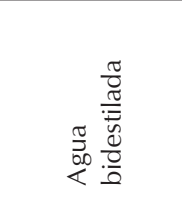 & 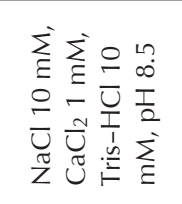 & 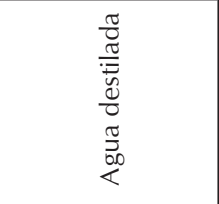 & 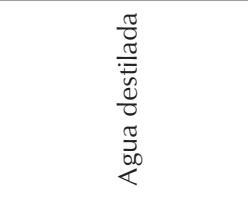 & 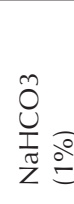 \\
\hline 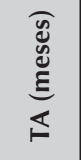 & $\bar{v}$ & $\stackrel{\text { r }}{Z}$ & $\bar{v}$ & $\bar{v}$ & $\stackrel{\alpha}{z}$ & $\bar{v}$ & $\bar{v}$ & - \\
\hline 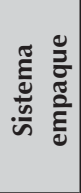 & 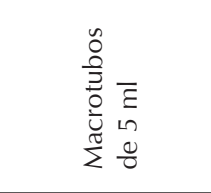 & 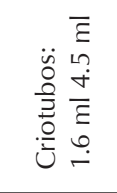 & 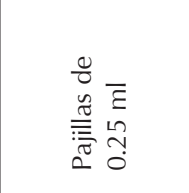 & 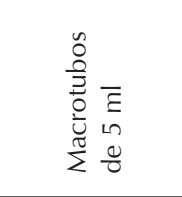 & 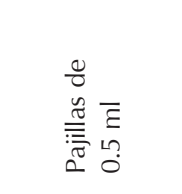 & 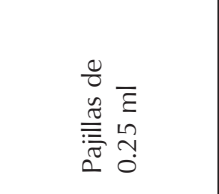 & 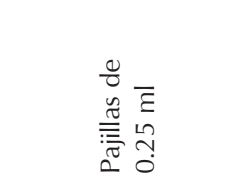 & 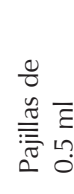 \\
\hline 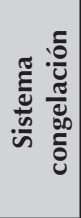 & 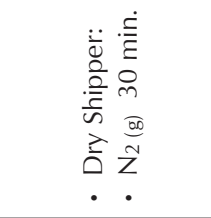 & 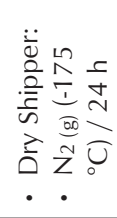 & 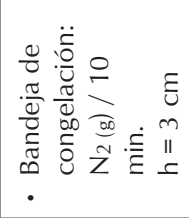 & 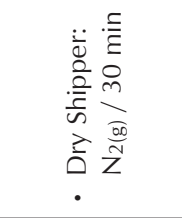 & 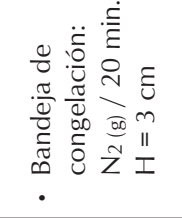 & 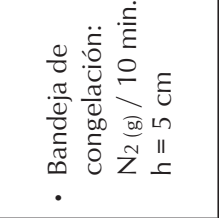 & 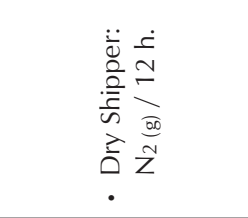 & 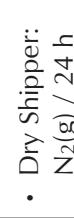 \\
\hline 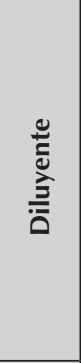 & 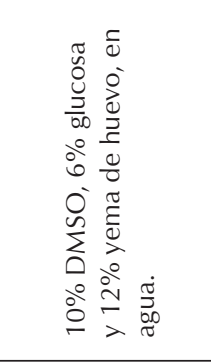 & 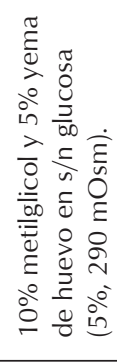 & 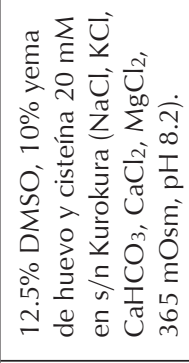 & 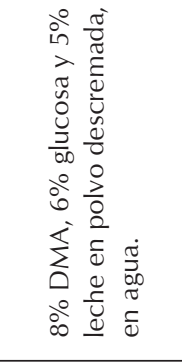 & 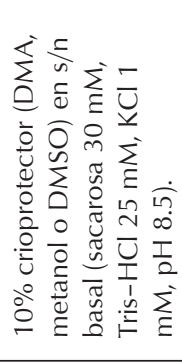 & 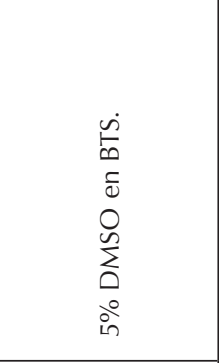 & $\begin{array}{l}\text { D } \\
\infty \\
\vdots \\
0 \\
0 \\
\sum_{0}^{n} \\
0 \\
\text { in }\end{array}$ & 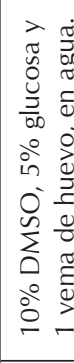 \\
\hline$\underset{\alpha}{z}$ & $\stackrel{m}{=}$ & $\stackrel{\mathscr{P}}{=}$ & $\stackrel{\mathscr{P}}{=}$ & $\stackrel{+}{+}$ & $\stackrel{\circ}{\ddot{\circ}}$ & $\stackrel{\sharp}{*}$ & $\stackrel{+}{+}$ & $\stackrel{\leftrightarrow}{\stackrel{0}{-}}$ \\
\hline 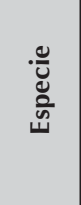 & 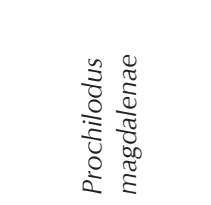 & 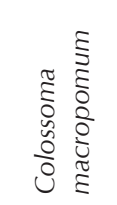 & 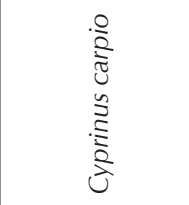 & 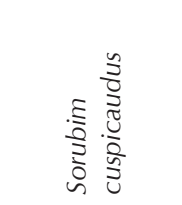 & 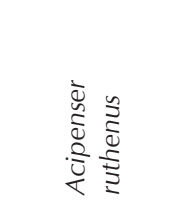 & 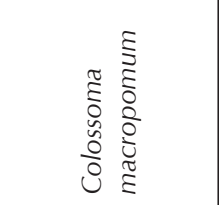 & 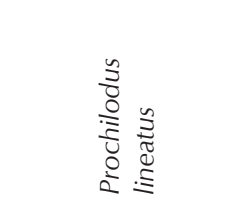 & 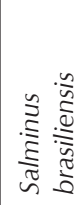 \\
\hline
\end{tabular}




\begin{tabular}{|c|c|}
\hline $\begin{array}{l}\frac{\pi}{0} \\
\frac{0}{0} \\
\frac{0}{2} \\
\frac{0}{2}\end{array}$ & 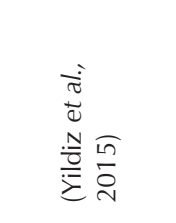 \\
\hline 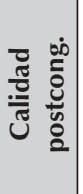 & 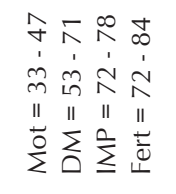 \\
\hline ๑ & 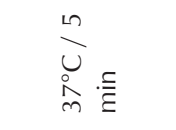 \\
\hline 就 & $\begin{array}{l}\widehat{o} \\
\stackrel{n}{0} \\
\stackrel{0}{U} \\
\stackrel{\pi}{Z}\end{array}$ \\
\hline 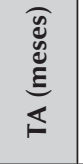 & 号 \\
\hline 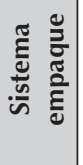 & 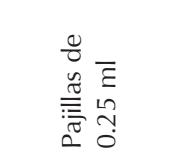 \\
\hline 苞 & 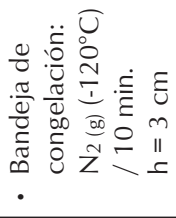 \\
\hline 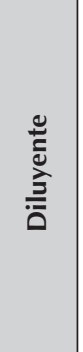 & 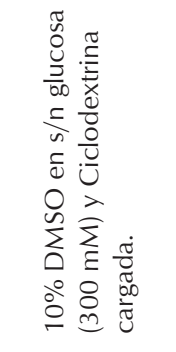 \\
\hline$\underset{\propto}{z}$ & $\stackrel{n}{\because}$ \\
\hline 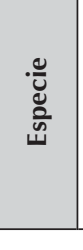 & 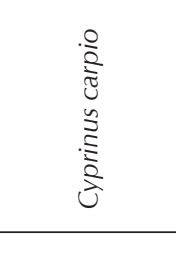 \\
\hline
\end{tabular}

(Ramalho-Santos et al., 2007); con base en ese porcentaje, el semen puede clasificarse en cinco categorías de calidad seminal, desde la Categoría 1 (0 - 20\% de células móviles) hasta la Categoría 5 (80 - 100\% de células móviles) (Boryshpolets et al., 2018). Por su parte, la duración de la motilidad se determina cronometrando el tiempo transcurrido en segundos, desde la activación de los espermatozoides hasta la suspensión del movimiento (Cruz-Casallas et al., 2006a). Pese a que el método de microscopía es rápido y sencillo, su reproducibilidad puede ser baja si el investigador que realiza la evaluación no es experimentado (Engel et al., 2019). Sin embargo, la subjetividad de la evaluación microscópica puede disminuirse considerablemente con el empleo de mano de obra cualificada y la determinación de la misma por una sola persona dentro de un mismo experimento.

En los últimos años, se han empleado otros tipos de microscopía con variaciones de iluminación, tales como, la microscopía de contraste (positivo o negativo) y microscopía de campo oscuro en combinación con luz estroboscópica, los cuales permiten obtener imágenes de mayor calidad (Figueroa et al., 2016; Boryshpolets et al., 2018).

Una forma más eficiente de medir la cinética espermática es mediante la incorporación de sistemas de Análisis de Esperma Asistido por Computadora (CASA, por sus siglas en inglés) con base en imágenes y videos tomados a una frecuencia $(\mathrm{Hz})$ y una duración (s) específica, según protocolo, siendo el Analizador de Clase de Esperma (SCA, por sus siglas en inglés) el equipo de generación CASA más popular, dada su efectividad validada. Además del porcentaje de motilidad (tanto masal como individual) y de la duración de la motilidad, los sistemas CASA permiten medir otras variables cinéticas tales como la velocidad curvilínea (VLC), la velocidad de línea recta (VSL), la velocidad de trayectoria promedio (VAP), el coeficiente de linealidad (LIN), el coeficiente de oscilación (WOB), el coeficiente de rectitud (STR), la amplitud del desplazamiento lateral de cabeza (ALH), el desplazamiento angular medio (MAD), la frecuencia de batido de la cola (BCF), entre otras (Aulesa et al., 2009; Amann y Waberski, 2014). Debido a que los sistemas CASA comerciales son costosos, se han desarrollado varias alternativas gratuitas. Wilson-leedy e Ingermann (2007) desarrollaron un complemento para el software Image y lo validaron en semen de pez cebra (Danio rerio); al comparar sus resultados con los obtenidos en sistemas CASA comerciales, la desviación estándar no superó el 10\%. En los últimos años se han desarrollado sistemas CASA de acceso libre y código abierto que, además de medir los diferentes componentes de motilidad, permiten evaluar el movimiento guiado de los espermatozoides en respuesta a estímulos 
externos, tales como la termotaxis, la reotaxis y la quimiotaxis (Alquézar-Baeta et al., 2019). Algunos sistemas CASA como CRISMAS, Hobson Sperm Tracker e ImageJ - CASA ya han sido probados en el semen de peces como el esturión esterlete (Acipenser ruthenus L.), la carpa común (Cyprinus carpio L.) y la trucha arcoíris (Oncorhynchus mykiss). Se encontró que los resultados de motilidad pueden verse significativamente alterados cuando se emplea diferentes sistemas CASA, incluso cuando se usan las mismas grabaciones de una muestra. Si bien es cierto que el CASA ofrece un análisis más amplio de la motilidad, sus resultados pueden estar influenciados de manera crítica por la calidad de grabación, el tiempo de análisis y la velocidad de fotogramas de la cámara, dando lugar a conclusiones erróneas (Boryshpolets et al., 2013).

\section{Morfología espermática}

El espermatozoide es el tipo de célula más diversa morfológicamente, inclusive entre ejemplares de la misma especie. Los espermatozoides de los peces son generalmente más pequeños que los espermatozoides de otros grupos de animales y se caracterizan por carecer de acrosoma, a excepción de los espermatozoides de los esturiones en peces óseos y de todas las especies de peces cartilaginosos. En general, el diámetro de la cabeza esférica o alargada de los espermatozoides de los peces oscila entre 3 - $4 \mu \mathrm{m}$, mientras que el del flagelo es de tan solo aproximadamente $0.5 \mu \mathrm{m}$ (Boryshpolets et al., 2018). Aunque, se reporta que los siluriformes suelen tener dimensiones más pequeñas, que están en el rango de 1.5 - 2.2 um para el diámetro de cabeza, y 20 - $30 \mu \mathrm{m}$ para la longitud de la cola (Borges et al., 2020). Se cree que la diversidad morfológica de los espermatozoides, en cuanto a tamaño, forma y comportamiento, es el mecanismo mediante el cual, la célula se adapta al entorno para garantizar su supervivencia. Una fuente directa de variabilidad espermática es la competencia espermática. Diversos estudios han demostrado que los espermatozoides de mayor longitud son más veloces y pueden fecundar más rápido el óvulo, sin embargo, los espermatozoides de menor tamaño son más resistentes a la congelación. Por consiguiente, existe una relación morfometría-criorresistencia (Fitzpatrick et al., 2010; Morales et al., 2016) y una relación morfología-fertilidad (Butts et al., 2011; Galo et al., 2019).

Se ha comprobado en varias investigaciones que los espermatozoides con morfología normal tienen mayores probabilidades de fecundar los óvulos y de sobrevivir hasta la fase final de la embriogénesis (Bobe y Labbé, 2010). Asimismo se ha evidenciado que las anormalidades morfológicas difieren en su impacto so- bre la fertilidad, algunas dificultan exclusivamente la capacidad de fertilización, mientras que otras como la desviación de cabeza en forma de pera impiden el desarrollo del embrión (Rodríguez-Martínez, 2019). Por ello, es importante determinar en las muestras de semen el porcentaje de normalidad y los tipos de anormalidades espermáticas. Las anormalidades pueden ser primarias (congénitas) o secundarias (adquiridas), siendo las secundarias las que indican el efecto de la crioconservación sobre la calidad seminal (Morales et al., 2016). Miliorini et al., (2011) clasificaron las anormalidades en las siguientes categorías, conforme al segmento dañado: 1) anormalidades de cabeza como la macrocefalia, la microcefalia, la cabeza degenerada y la cabeza separada; 2) anormalidades de pieza media como la gota citoplasmática proximal y la pieza media degenerada; y 3) anormalidades de cola como la gota citoplasmática distal, la cola doblada, la cola rota, la cola enroscada y la cola separada o tocón.

La morfología se suele evaluar por microscopía (ya sea óptica, de contraste de fase o de campo oscuro) gracias a múltiples métodos de tinción como el Diff-Quik, el Ziehl-Neelsen, el rosa de bengala, entre otros, que permiten la identificación de los espermatozoides en el campo visual (Butts et al., 2011; López-Hernández et al., 2018). La forma convencional de analizar las muestras es mediante observación subjetiva, aunque es un proceso demorado cuya precisión depende de la destreza del investigador (Engel et al., 2019). En los últimos años se ha hecho uso de sistemas computarizados tipo CASA para el análisis de imágenes tomadas con una cámara digital incorporada al microscopio.

Las técnicas de microscopía óptica asistidas por CASA tienen la ventaja de que arrojan los resultados de forma rápida, automática y objetiva (Figueroa et al., 2016). Los sistemas CASA comprenden un módulo de morfología, que contrasta tanto la morfología como la morfometría de los espermatozoides observados contra un patrón de normalidad establecido según protocolo específico para la especie (Amann y Waberski, 2014; Alquézar-Baeta et al., 2019). El Analizador de clase de esperma (SCA) es un equipo de generación CASA que calcula valores de morfología tales como el porcentaje de espermatozoides normales, el índice de teratozoospermia, el índice de deformidad y medidas individuales tales como la longitud, la anchura, el ángulo de inserción medio de la cola, entre otras (Aulesa et al., 2009). Recientemente, se han desarrollado softwares automatizados de análisis de morfología de esperma (ASMA, por sus siglas en inglés) asistidos por computadora, que permite una rápida obtención de resultados. Sin embargo, estos sistemas de ASMA son costosos, lo que dificulta su asequibilidad. A raíz de 
esto, se ha desarrollado un ASMA complemento para el software de código abierto ImageJ, que permite obtener mediciones morfológicas de la cabeza del esperma tales como, la longitud y el ancho, sin diferencias estadísticamente significativas con las mediciones manuales (Butts et al., 2011).

\section{Ultraestructura}

El término ultraestructura espermática hace referencia a la morfología estructural que solamente puede ser observada mediante microscopía electrónica. Dada su especificidad, es ampliamente usada en sistemática y filogenia (Rodao et al., 2016).

La ultraestructura de los espermatozoides de los peces varía entre taxones. La ultraestructura de la cabeza del espermatozoide puede variar en cuanto a la forma del núcleo, la apariencia de la cromatina nuclear, el tamaño y la distribución de las áreas de electrones, la forma y el tamaño de la fosa nuclear, la disposición de los centriolos, y la presencia de estructuras especializadas asociadas con los centriolos. En la pieza media, las diferencias están relacionadas principalmente con el tamaño, la cantidad y la apariencia de las mitocondrias. La distribución de las mitocondrias en la pieza media depende del ángulo de inserción del flagelo en la cabeza; ya que cuando la inserción es oblicua, el número de mitocondrias es menor en la región con el ángulo agudo y mayor en la región con el ángulo obtuso. Finalmente, el flagelo de los peces, que consiste en un axonema con la disposición clásica de nueve dobletes periféricos y un par central de microtúbulos (patrón 9 + 2) unidos por nexina con dineínas laterales, puede tener una o más expansiones laterales de la membrana celular (Rodao et al., 2016; Dzyuba et al., 2017). Según Gillies et al., (2013), el papel evolutivo de las expansiones o aletas laterales es permitir una mayor eficiencia hidrodinámica de los espermatozoides.

La ultraestructura de los espermatozoides de los peces está fuertemente influenciada por el tipo de fertilización. Los espermatozoides con fertilización interna generalmente tienen núcleos alargados y una región intermedia más grande con muchas mitocondrias; mientras que los espermatozoides con fertilización externa regularmente tienen núcleos esféricos más pequeños, una pieza media más corta con pocas mitocondrias (generalmente de 1 a 6) dispuestas en una sola capa alrededor de la base del flagelo, y pueden estar mono o biflagelados (Rodao et al., 2016).

Los tipos de microscopía empleados para evaluar la ultraestructura son la microscopía electrónica de barrido (SEM) y la microscopía electrónica de transmisión (TEM), que son metodologías altamente versátiles para la caracterización no destructiva de materiales 2D y 3D desde la micro y la nanoescala. Los microscopios SEM y TEM generan un haz de electrones altamente enfocado, que impacta la muestra dentro de una cámara de vacío. Sin embargo, los microscopios SEM están diseñados principalmente para examinar la superficie del material (como los microscopios de luz de reflexión), mientras que los microscopios TEM están diseñados principalmente para examinar la estructura interna de las muestras (como los microscopios de luz de transmisión). La versión híbrida de SEM y TEM recibe el nombre de microscopía electrónica de transmisión de exploración (STEM) y sólo está disponible en equipos modernos (Inkson, 2016).

Ya se han realizado algunos estudios de ultraestructura espermática en varias especies de peces dulceacuícolas, tales como: Leiarius marmoratus (Borges et al., 2020), Lates niloticus (Kahwa et al., 2019), Acipenser dabryanus (Li et al., 2018), Piaractus mesopotamicus, Brycon orbignyanus, Salminus brasiliensis, Prochilodus lineatus (Murgas et al., 2017), Brachymystax lenok tsinlingensis (Guo et al., 2016), Austrolebias spp. (A. affinis, A. bellottii, A. charrúa, A. luteoflammulatus, A. melanoorus, A. nigripinnis, A. reicherti, $A$. vazferreirai) (Rodao et al., 2016), Brycon vermelha (Faustino et al., 2015), Misgurnus anguillicaudatus (Yang et al., 2014), Brycon nattereri (Viveiros et al., 2012), Gymnocorymbus ternetzi, Hyphessobrycon bifasciatus, Hyphessobrycon eques (Prieto et al., 2008).

\section{Viabilidad}

Es considerada la prueba de calidad con mayor poder predictivo sobre la fertilidad de un ejemplar, ya que indica el porcentaje de espermatozoides vivos en una muestra. Suele evaluarse por microscopía óptica o microscopía de epifluorescencia, luego de tinción diferencial (Ramalho-Santos et al., 2007). El conteo de células viables puede hacerse manualmente, con un contador electrónico o mediante sistemas CASA (AIquézar-Baeta et al., 2019). Se conocen principalmente dos ensayos de exclusión de espermatozoides (vivos/ muertos): el ensayo de eosina - nigrosina y el ensayo de SYBR / PI (Ramalho-Santos et al., 2007).

El ensayo de tinción con eosina - nigrosina, es un método de microscopía óptica propuesto inicialmente por Blom (1950) y modificado por varios autores. Los espermatozoides son impermeables a ambos colorantes, eosina y nigrosina, por ende, sólo son teñidos cuando presentan daño en la membrana celular y la eosina en- 
tra al citoplasma. La nigrosina es la encargada de proporcionar el contraste oscuro a los espermatozoides visualizados. La diferenciación entre espermatozoides vivos y muertos se hace por exclusión, puesto que los espermatozoides vivos permanecen incoloros, mientras que los muertos se tiñen de rojo. Los espermatozoides moribundos, por el contrario, exhiben cierto grado de coloración en la base de la cabeza (RamalhoSantos et al., 2007).

El ensayo de SYBR/PI, también llamado LIVE/DEAD se basa en una doble tinción de unión al ADN. El SYBR-14 es permeable a la membrana celular y, por ende, penetra a los espermatozoides independientemente del estado de integridad de la membrana, tiñéndolos de color verde fluorescente. Por el contrario, el yoduro de propidio (PI) sólo tiñe de color rojo los núcleos de los espermatozoides muertos por integridad de membrana comprometida. Dado que el PI está más concentrado, las células no viables exhiben sólo el color rojo. Sin embargo, cuando los espermatozoides se encuentran en un nivel medio de vitalidad, es decir, moribundos, exhiben fluorescencia amarillo-anaranjada (RamalhoSantos et al., 2007). Algunos reportes de viabilidad espermática postdescongelación en peces dulceacuícolas son mostrados en la Tabla 1.

\section{Aspectos celulares y bioquímicos}

\section{Integridad de membrana plasmática}

La membrana plasmática consiste en una delgada bicapa de lípidos anfipáticos que separa y protege la célula del medio extracelular y es responsable, junto con las proteínas transmembrana, del intercambio celular (Cartón-García et al., 2013). La integridad de la membrana plasmática y su permeabilidad selectiva son fundamentales para la supervivencia celular, y está directamente correlacionada con la viabilidad espermática (Figueroa et al., 2016).

Durante las etapas de congelación y descongelación, la membrana plasmática experimenta mediante diferentes mecanismos, ya sea osmóticos, mecánicos u oxidativos, alteraciones fisicoquímicas como reestructuración, desintegración, ruptura, deshidratación, cambios de fase de los fosfolípidos, modificaciones de las interacciones lípido-proteína y peroxidación lipídica, entre otros, que afectan su integridad (Watson et al., 2001; Figueroa et al., 2016). Martínez-páramo et al. (2012) sugieren que el efecto nocivo del shock osmótico sobre la integridad de membrana plasmática es más influyente que el del estrés oxidativo. Aunque independientemente de la fuente de lesión, los esperma- tozoides con integridad de membrana comprometida presentan disfunción celular, asociada principalmente a la reducción de ciertas capacidades como la osmorregulación, la motilidad, la resistencia a la congelación y la fertilidad (Martínez-páramo et al., 2012).

La resistencia celular a la congelación y al estrés osmótico puede mejorarse mediante la alteración de las propiedades de transición de fase de la membrana celular por acción de ciclodextrinas cargadas con lípidos o liposomas unilamelares. La membrana celular se modifica de tal forma que se aumenta la proporción colesterol/fosfolípidos, la cual es directamente proporcional a la fluidez de la membrana a bajas temperaturas. La proporción ideal de colesterol/fosfolípidos ha de ser cercana a 1:1. Lo anterior conlleva a la reestructuración de la membrana, la modificación de los procesos fisiológicos y, como resultado, una mayor supervivencia celular a la crioconservación. Sin embargo, el éxito de la operación depende del tipo y dosis de ciclodextrinas, de la longitud de cadena de los lípidos incorporados y de la especie con que se esté trabajando (Purdy y Graham, 2015).

La integridad de la membrana plasmática se puede evaluar mediante la capacidad de penetración de ciertos colorantes a la célula, ya que, al ser impermeable la membrana, sólo se tiñen las células con integridad de membrana comprometida. Las tinciones más populares se realizan con eosina/nigrosina, anilina/eosina y eosina-verde rápido (CFC). Recientemente, se ha incorporado marcadores fluorescentes de ADN como Hoechst 33258, yoduro de propidio (PI) y kits de fluorescencia dual, tales como SYBR-14/yoduro de propidio (SYBR-14/PI), diacetato de 6-carboxifluoresceína/ yoduro de propidio (6-CFDA/PI), Carboxi-SNARF/yoduro de propidio, y calceína-AM/homodímero de etidio - EthD-1 (Partyka et al., 2012). Los resultados se expresan en términos de porcentaje de células viables, es decir, células con integridad de membrana.

\section{Integridad de mitocondria}

Las mitocondrias son organelas que pueden tener forma cilíndrica, esférica, ovoide o irregular. Se encuentran ubicadas en la pieza media del espermatozoide, adheridas en un patrón helicoidal, cónico, circular o irregular. Sus dimensiones, su distribución en la pieza media y su número dentro del espermatozoide pueden variar conforme a múltiples factores, como por ejemplo, el tipo de taxón (Figueroa et al., 2017).

Las mitocondrias juegan un papel clave en el metabolismo espermático, ya que son la principal fuente de energía celular. A través de la fosforilación oxidativa 
(OXPHOS) y el ciclo de los ácidos tricarboxílicos (ciclo de Krebs), las mitocondrias producen el ATP necesario para suplir los requisitos energéticos de la célula, principalmente, para llevar a cabo la actividad flagelar (Figueroa et al., 2017). El potencial de la membrana mitocondrial está correlacionado positiva y significativamente con la motilidad espermática, la integridad de ADN nuclear y la tasa de fertilización (Giaretta et al., 2017; Figueroa et al., 2019). No obstante, las estructuras mitocondriales son sensibles al frío y pueden verse drásticamente afectadas durante la congelación (Isachenko et al., 2018). Figueroa et al. (2019) sugieren que la crioconservación induce una reducción en la calidad y funcionalidad general de los espermatozoides a través de la interrupción de la ultraestructura y función mitocondrial, lo que conduce al agotamiento de la energía y al aumento del estrés oxidativo. Aunque, el daño crioinducido no llega a comprometer la secuencia y la estructura del ADN mitocondrial.

De acuerdo con Cabrita et al., (2014) y Figueroa et al., (2017), las mitocondrias de los espermatozoides criopreservados de esturión esterlete (Acipenser ruthenus), carpa común (Cyprinus carpio), trucha arcoíris (Oncorhynchus mykiss) y trucha de arroyo (Salvelinus fontinalis) presentan una alta sensibilidad a la crioconservación. Por ejemplo, los espermatozoides crioconservados de trucha pueden presentar una reducción de hasta el $60 \%$ del potencial de membrana mitocondrial.

Para evaluar el potencial mitocondrial, se usan generalmente dos sondas, MitoTracker o Rodamina 123, que determinan la presencia o ausencia de potencial, al teñir sólo las mitocondrias funcionales. Sin embargo, una mejor opción es el catión fluorescente JC-1, que además de evaluar la presencia o ausencia de potencial mitocondrial en la célula, permite clasificar las mitocondrias por nivel de potencial, ya que tiñe de color rojo las mitocondrias con alto potencial y de verde las mitocondrias con bajo potencial (Cunha et al., 2015).

\section{Concentración de ATP}

Además de sus funciones motoras, el ATP desempeña un papel inhibidor de la actividad ATPasa de la dineína, cuando se encuentra en concentraciones fisiológicas, antes de la activación. La inhibición de la actividad ATPasa se hace para evitar que los brazos de dineína causen el deslizamiento de los microtúbulos y alteren la ultraestructura del flagelo (Dzyuba et al., 2017).

Dzyuba et al., (2016), sugieren que los peces, independientemente de su estructura taxonómica y de su modo de activación (iónico u osmótico), poseen sistemas similares de suministro de energía para la actividad flagelar. El ciclo del ácido tricarboxílico (ciclo de Krebs) y la fosforilación oxidativa son las vías metabólicas clave que sostienen el metabolismo basal en los espermatozoides; ambas ocurren en la matriz mitocondrial y son las encargadas de producir energía química en forma de ATP a partir del Acetil-CoA, producto de la descarboxilación oxidativa del piruvato. En especial, la fosforilación oxidativa es la encargada del mantenimiento de las concentraciones de ATP durante el metabolismo basal (Dzyuba et al., 2017). La adenina juega un papel clave en la respiración celular, ya que en forma de cofactores como nicotinamida adenina dinucleótido (NAD) y flavin adenina dinucleótido (FAD) facilita el transporte de electrones durante la fosforilación oxidativa. Además, la adenina puede convertirse en ATP mediante tres fosforilaciones enzimáticas consecutivas con AK (Abed-Elmdoust et al., 2019).

El ciclo de Krebs y la fosforilación oxidativa dependen del consumo de oxígeno debido a que la glucólisis necesaria para producir el piruvato es mucho más efectiva en condiciones aerobias que en condiciones anaerobias (Dzyuba et al., 2017). Durante la actividad flagelar, el consumo de oxígeno aumenta y llega a su máximo, mientras que el contenido intracelular de ATP disminuye rápidamente debido a que la tasa de producción de ATP es insuficiente para compensar el gasto energético. Cuando los espermatozoides son crioconservados, la actividad flagelar se ve principalmente afectada ya que disminuyen tanto el consumo de oxígeno como las reservas de ATP a causa del daño mitocondrial ocurrido durante la congelación y/o descongelación (Figueroa et al., 2019). Empero, el consumo total del contenido de ATP podría prolongarse mediante una disminución sucesiva de la osmolaridad del medio de activación, ya que existe subpoblaciones de espermatozoides dentro de una misma muestra que difieren en su sensibilidad al nivel de hipotonicidad requerido para su activación (Boryshpolets et al., 2009).

El contenido de ATP se puede medir por bioluminiscencia o por cromatografía líquida de alta eficacia (HPLC) y por Resonancia magnética nuclear de fósforo (P-RMN). La técnica de luminiscencia que utiliza los luminómetros de microplaca es fácil y rápida, ya que puede procesarse a través de kits de análisis comercial confiables y los resultados pueden generarse en dos o tres horas. En cuanto al HPLC, la ventaja reside en la evaluación conjunta de los contenidos de ADP y AMP, que definen conjuntamente la carga energética de ATP (AEC). AEC corresponde al porcentaje de nucleótidos ricos en energía divididos por el grupo adenílico y puede considerarse como el contenido intracelular de 
energía disponible. Valores de AEC entre el 95 - 80\% indican que las células presentan condiciones óptimas; valores de $\mathrm{AEC}$ entre el 50 - 70\% indican condiciones intermedias, que aún pueden aumentarse; y valores por debajo del $50 \%$ indican que la célula presenta un nivel de energía disponible muy bajo, lo que limita sus funciones. Por su parte, el P-RMN permite un estudio más amplio de los fosfágenos (compuestos macroérgicos), tales como CrP (Dzyuba et al., 2010).

\section{Capacidad antioxidante}

El estrés oxidativo ocurre cuando la actividad oxidativa de las especies reactivas de oxígeno (ROS) excede la capacidad antioxidante disponible localmente. Este desequilibrio redox provoca daños celulares que pueden llegar a ser letales (Sharma et al., 2013). Dentro de los daños celulares ocasionados se destaca la oxidación de lípidos y proteínas de membrana, la disfunción espermática, el detrimento de la pieza media, el daño estructural del axonema, la fragmentación del ADN, la infertilidad, el deterioro mitocondrial, la inhibición de enzimas implicadas en la respiración celular (tales como las fosfatasas y las quinasas), y en casos extremos, la apoptosis (Cabrita et al., 2011; Kutluyer et al., 2014). El deterioro mitocondrial y la inhibición de enzimas implicadas en la respiración celular son de especial relevancia, puesto que limitan el suministro de energía para el movimiento flagelar (Dzyuba et al., 2017).

Las fuentes de ROS pueden ser tanto intrínsecas como extrínsecas, siendo las primeras necesarias, en cierta medida, para llevar a cabo algunos procesos fisiológicos como la maduración espermática y la capacidad de fertilización (Dzyuba et al., 2014; Rodríguez-Martínez, 2019). Las principales fuentes intrínsecas de ROS son los aniones superóxido producidos durante la fosforilación oxidativa en las mitocondrias, la oxidasa transmembrana $\mathrm{NAD}(\mathrm{P}) \mathrm{H}$, y el óxido nítrico producido por la óxido-nítrico sintasa dentro de la membrana plasmática. Las fuentes extrínsecas incluyen los leucocitos (granulocitos), la contaminación ambiental, la interacción con sustancias químicas en laboratorio, entre otras (Sharma et al., 2013).

En particular, el semen de los peces es bastante inestable y vulnerable al ataque oxidativo por ROS debido al alto contenido de ácidos grasos monoinsaturados y poliinsaturados en la membrana celular espermática. Sin embargo, existe especies de peces que son resistentes al estrés oxidativo, hasta el punto de que no llegan a encontrarse diferencias significativas en cuanto al grado de peroxidación lipídica entre el semen fresco y el crioconservado. La trucha marrón (Salmo trutta) y la trucha arcoíris (Oncorhynchus mykiss) son un claro ejemplo de especies con semen de gran capacidad antioxidante (Lahnsteiner et al., 2011).

El semen de los peces contiene de manera natural un sistema antioxidante conformado por componentes enzimáticos (glutatión peroxidasa, glutatión reductasa, superóxido dismutasa, catalasa) y no enzimáticos (ácido ascórbico, ácido úrico, tocoferol, $\beta$-carotenos, selenio, zinc) que actúan como captadores de ROS y protegen la estructura celular (Martínez-Páramo et al., 2012). Dado que los espermatozoides tienen un bajo contenido de citoplasma, su principal defensa contra el estrés oxidativo son las proteínas y compuestos de bajo peso celular disponibles en el plasma seminal, principalmente ácido ascórbico, ácido úrico y catalasa (Lahnsteiner et al., 2010; Dzyuba et al., 2014). Sin embargo, la protección contra el estrés oxidativo durante la crioconservación es insuficiente, ya que al disolver el semen en el diluyente, la concentración de antioxidantes en el plasma seminal disminuye (Cabrita et al., 2011). Por ello, para que el estrés oxidativo sea el mínimo, el tiempo de manipulación del semen durante su procesamiento y uso no debe ser muy prolongado (Lahnsteiner et al., 2011).

Para aminorar el estrés oxidativo, algunos investigadores han suplementado los diluyentes de crioconservación con antioxidantes, mientras que otros los han incorporado en la dieta de los ejemplares. Aunque, el efecto de los antioxidantes sobre la calidad seminal varía dependiendo de la especie y el protocolo de crioconservación empleado. Se reporta el uso de vitaminas, enzimas, polifenoles y aminoácidos como suplementos antioxidantes (Cabrita et al., 2011; Lahnsteiner et al., 2011; Kutluyer et al., 2014), siendo de especial importancia la transferrina (Li et al., 2010). No obstante, en ocasiones, a causa de la interacción con metales de transición, los antioxidantes pueden desencadenar un efecto adverso conocido como oxidación proactiva e incrementar el estrés oxidativo (Cabrita et al., 2011).

Para la evaluación del estrés oxidativo en el semen, se deben cuantificar tanto la capacidad antioxidante total (TAC, por sus siglas en inglés) como las ROS:

La determinación de TAC se puede efectuar mediante la evaluación de la capacidad de los antioxidantes en la muestra para inhibir la oxidación de una sustancia en particular, como el ABTS (Kashou et al., 2012). Algunas de las actividades enzimáticas que se pueden cuantificar son glutatión peroxidasa (GPx), glutatión reductasa (GSR), superóxido dismutasa (SOD) y catalasa (CAT). Asimismo, los niveles de DNPH dan cuenta 
del estado de oxidación de las proteínas (ShaliutinaKolešová et al., 2015).

Las ROS o sus productos oxidados se pueden medir mediante ensayos directos e indirectos. Dentro de los ensayos directos se encuentra la quimioluminiscencia, la prueba de nitroazul de tetrazolio, la reducción de citocromo C, la citometría de flujo, la resonancia de espín electrónico y el ensayo basado en naranja de xilenol. Los ensayos indirectos incluyen la medición de la mieloperoxidasa, el potencial redox, los niveles de peroxidación lipídica, las quimiocinas y los antioxidantes. La quimioluminiscencia es el ensayo directo más utilizado para cuantificar el nivel global de ROS. Para ello, emplea dos sondas: luminol y lucigenina. El luminol reacciona con ROS tanto intracelulares como extracelulares, mientras que la lucigenina muestra más afinidad por los aniones superóxido liberados extracelularmente (Kashou et al., 2012).

En particular, la peroxidación lipídica se puede evaluar mediante la cuantificación del malondialdehído (MDA), un producto final de la peroxidación lipídica de ácidos grasos poliinsaturados. La prueba más común es el test de sustancias reactivas al ácido tiobarbitúrico (TBARS), que se basa en la reacción del malondialdehído (MDA) con el ácido tiobarbitúrico (TBA) para generar sustancias fluorescentes detectables por espectrofluorometría, usando como patrón 1,1,3,3-tetrametoxipropano. No obstante, dada la inespecificidad del TBARS, se están empleando kits comerciales alternativos como el Oxis Bioxytech y el Bodipy (Cabrita et al., 2014).

\section{Integridad de cromatina (ADN)}

La integridad del ADN espermático es esencial para la transferencia de información genética a la próxima generación (Shaliutina-Kolešová et al., 2015), e influye representativamente sobre el desarrollo embrionario y la fertilidad. Infortunadamente, durante la congelación del semen, los espermatozoides sufren estrés oxidativo por acción de las especies reactivas de oxígeno (ROS) intrínsecas, que atacan las pentosas de los nucleótidos y provocan la fragmentación del ADN. El ADN espermático es especialmente susceptible al daño oxidativo, ya que la estructura altamente condensada del material nuclear obstaculiza la reparación enzimática de las cadenas de nucleótidos. Los espermatozoides con ADN fragmentado presentan integridad de membrana comprometida y disfunción celular, por lo tanto, son incapaces de fertilizar exitosamente los ovocitos tanto en la reproducción natural como en la asistida. Se ha reportado una correlación considerablemente alta entre la eficiencia de fertilización y la susceptibilidad al daño genético (Cabrita et al., 2011; Sharma et al., 2013).

La fragmentación del ADN espermático tiene diversos orígenes, que pueden ser intrínsecos o extrínsecos. Los orígenes intrínsecos ocurren en su mayoría durante la espermatogénesis, siendo de importancia las aberraciones en la recombinación, la maduración anormal de espermátidas por protaminación ineficiente, la apoptosis abortiva y el estrés oxidativo. Los orígenes extrínsecos, por su parte, están relacionados con factores externos a la célula, tales como la edad del reproductor, la temperatura exterior, la contaminación ambiental, las infecciones bacterianas, el procesamiento del semen y la embriogénesis (Gunes y Sertyel, 2018).

Los antioxidantes juegan un papel importante en la protección del ADN de los espermatozoides, ya que pueden contrarrestar el ataque oxidativo e inclusive, neutralizar los efectos inducidos por la crioconservación. En consecuencia, varios investigadores han optado por suplementar los extensores de crioconservación con varios tipos de antioxidantes específicos para protección del ADN, tales como la taurina e hipotaurina (Cabrita et al., 2011).

Actualmente existe varios métodos para el estudio de la integridad de la cromatina utilizando diferentes enfoques, tales como (a) el ensayo de electroforesis unicelular en gel (conocido como cometa), (b) el ensayo de etiquetado terminal con trifosfato de desoxiuridina vía desoxinucleotidil transferasa (conocido como TU$\mathrm{NEL}$ ), (c) el análisis de secuencias específicas de ADN que utilizan RT-PCR (Cabrita et al., 2010), (d) la prueba de naranja de acridina (AOT), (e) el ensayo de incorporación de $3 \mathrm{H}$-actinomicina $\mathrm{D}$ (3H-AMD) marcado con tritio, (f) la traducción de muescas in situ (ISTN), (g) la hibridación fluorescente in situ (DBD-FISH), (h) la prueba de dispersión de cromatina espermática (SCD), entre otros (Rodríguez-Martínez, 2019). Además, existe ensayos que determinan la susceptibilidad del ADN al daño exógeno tras exposición a condiciones desnaturalizantes, tales como el ensayo de estructura cromática de esperma (SCSA) y el ensayo del cometa en condiciones alcalinas, los cuales permiten predecir anomalías como las aberraciones en la estructura y en el empaquetamiento de la cromatina, y las falencias de los mecanismos protectores y estabilizadores del ADN (Sharma et al., 2013). La mayoría de los métodos anteriores usan microscopía de fluorescencia mientras que, SCSA y TUNEL trabajan con citometría de flujo (Rodríguez-Martínez, 2019). 
El ensayo del cometa, es uno de los métodos más comunes para la evaluación de la integridad de cromatina; consta de la observación de una muestra de semen por microscopía de fluorescencia, luego de tinción con DAPI diluido (4',6-diamidino-2-fenilindol), previa lisis celular y corrida electroforética en gel de agarosa. La cromatina marcada con DAPI toma el aspecto de un cometa de color verde fluorescente, en el que la cabeza corresponde a ADN íntegro y la cola corresponde a fragmentos de ADN. El porcentaje de ADN fragmentado por célula se determina mediante procesamiento de imágenes. Este método fue desarrollado inicialmente para el software KOMET, pero ya existen alternativas de libre acceso, como ImageJ, que permiten obtener resultados semejantes (Cabrita et al., 2010).

El ensayo del TUNEL es otro de los métodos más populares para la evaluación de la integridad de cromatina. Las principales fuentes de fragmentación del ADN, detectables por TUNEL parecen ser el daño de los radicales libres por estrés oxidativo y la apoptosis abortiva. La fragmentación de la cromatina es detectada mediante marcado enzimático de los fragmentos de ADN por acción de la deoxinucleotidil transferasa (TdT). La TdT marca los terminales 3'-OH libres de los fragmentos de ADN con nucleótidos modificados, por lo general, trifosfato de desoxiuridina (dUTP). Los cuerpos apoptóticos son representativamente teñidos ya que presentan múltiples terminales 3'-OH libres, contrario a los núcleos normales o proliferativos, que tienen números relativamente insignificantes de extremos libres 3'-OH. Las células teñidas se pueden visualizar por microscopía de luz, aunque para mayor practicidad, se suele emplear citometría de flujo, que detecta la fluorescencia intracelular del dUTP previamente marcado con fluorocromos. El isotiocianato de fluoresceína (FITC) es el fluorocromo más empleado, el cual se aplica en conjunto con el yoduro de propidio (PI) para aumentar el contraste. Los resultados se expresan como porcentaje de células con integridad de ADN comprometida (Sharma et al., 2013).

El SCSA es el método más empleado para la evaluación del daño potencial del ADN espermático. Este método se basa en el principio de que las células morfológicamente anormales presentan alteraciones en la estructura de la cromatina y, por ende, son más susceptibles a desnaturalización por temperatura y pH. SCSA consta de la observación de una muestra por citometría de flujo, luego de tinción con naranja de acridina (AO), previa inducción de la desnaturalización del ADN susceptible al daño mediante tratamientos térmico y ácido. AO tiñe de verde el ADN intacto y de rojo los fragmentos de ADN. AO suele aplicarse en conjunto con bromuro de etidio para aumentar el contraste. Las moléculas de $\mathrm{AO}$ son muy pequeñas, por lo que es bastante probable que penetren en toda la estructura de cromatina nuclear altamente compacta (Evenson, 2018).

Aparte del material genético, el espermatozoide contribuye con componentes epigenéticos, que regulan la expresión génica de una célula sin alterar la codificación de ADN, y son esenciales para el desarrollo embrionario temprano. Algunos de los procesos epigenéticos son la metilación del ADN, la retención selectiva de histonas, la organización del dominio del bucle de ADN en el núcleo, la presencia de proteínas teca perinucleares y micro-ARNs, entre otros (RodríguezMartínez, 2019).

\section{Perfil metabólico}

Se ha reportado que la crioconservación induce cambios en el metaboloma del semen, los cuales sirven como marcadores de lesiones criogénicas y de alteraciones en las rutas metabólicas (Nynca et al., 2015a). Por lo tanto, un estudio metabolómico puede ser preciso para la comparación de las fortalezas y debilidades de las diferentes técnicas de congelación (AbedElmdoust et al., 2019).

La determinación de compuestos relacionados con la creatina está directamente relacionada con la regeneración del ATP post-activación. Se espera que a medida que la Creatina Fosfato $(\mathrm{CrP})$ sea desfosforilada durante la regeneración del ATP, los niveles de Creatina y creatinina aumenten. Caso contrario, podría deberse a la degradación de los compuestos de creatina en metabolitos más pequeños como el guanidoacetato, a causa de la congelación; por ende, el guanidoacetato puede servir como indicador de la descomposición criogénica de los compuestos de creatina. Por otro lado, los niveles de acetato pueden indicar el efecto devastador de la congelación sobre la respiración celular, ya que se ha demostrado que este metabolito (de gran importancia en la síntesis de acetil-CoA) disminuye en el semen crioconservado en contraste con el semen fresco; aunque se ha reportado que las altas tasas de congelación disminuyen la degradación del acetato. La adenina también es altamente sensible a las bajas temperaturas, independientemente del método de congelación, por lo que el contenido de adenina en los espermatozoides crioconservados puede variar de mínimo a nulo. Por su parte, la betaína es un indicador de estrés oxidativo ya que presenta actividad antioxidante; por ende, altos niveles de betaína muestran que el semen ha sufrido menos hipoxia y peroxidación lipídica mientras que, bajos niveles evidencian el agotamiento de la betaína durante la neutralización de los 
radicales libres. Los niveles altos de glicina en tratamientos crioconservados evidencian la degradación de la betaína a causa de la congelación, lo que explica la mayor susceptibilidad del semen crioconservado al ataque oxidativo (Abed-Elmdoust et al., 2019).

El estudio de los productos proteicos expresados por el genoma ha sido ampliamente abordado en la última década (Rodríguez-Martínez, 2019). Los estudios proteicos son muy útiles para la determinación de cambios en la morfología y las funciones espermáticas a causa de la congelación; aunque es una tarea tediosa, ya que el flagelo utiliza más de 500 componentes proteicos para su funcionamiento (Dzyuba et al., 2017). Un estudio del perfil proteico se puede hacer mediante western blot (electrotransferencia), espectrometría de masas MALDI-TOF, o cromatografía líquida-espectrometría de masas (LC-MS), previa separación de las proteínas con SDS-PAGE y/o electroforesis bidimensional en gel de poliacrilamida (Li et al., 2010; Nynca et al., 2015a).

\section{Fertilidad}

El protocolo general de fertilización implica la mezcla de espermatozoides quiescentes con un lote de ovocitos, seguido de activación seminal e incubación en condiciones óptimas para la especie (Yasui et al., 2012). En algunos protocolos, la activación va seguida del tratamiento con ácido tánico, previo a la incubación, para eliminar la pegajosidad de los ovocitos (Yildiz et al., 2015). La fertilidad está ampliamente influenciada por la motilidad y la velocidad espermática, que a su vez dependen del potencial de membrana mitocondrial y de la osmorregulación del calcio intracelular (Viveiros et al., 2010; Figueroa et al., 2019). Sin embargo, la movilidad y velocidad espermática no son garantes de fertilización si el espermatozoide no encuentra el micrópilo del ovocito en poco tiempo, tarea que sólo puede finiquitarse gracias a la quimiotaxis celular (Dzyuba et al., 2017).

La determinación de la fertilidad es la prueba clave en la evaluación de la calidad seminal (Galo et al., 2019). El porcentaje de fertilidad se calcula como el cociente entre la proporción de embriones viables y el número total de huevos que fueron fecundados (Draper y Moens, 2009). Aunque también se suelen aplicar otros indicadores relacionados, tales como, el porcentaje de huevos eclosionados (Kopeika et al., 2007) y el porcentaje de embriones en estado de vesícula óptica, ambos en relación con el número total de huevos (Lahnsteiner et al., 2011).
Las condiciones de incubación influyen en la fertilización y embriogénesis, y dichas condiciones pueden variar de acuerdo con la especie. Algunas de las condiciones reportadas son las siguientes: $9{ }^{\circ} \mathrm{C}$ durante 30 - 35 días para Salvelinus fontinalis; 28 - 30 días para Oncorhynchus mykiss (Lahnsteiner et al., 2011; Kutluyer et al., 2014); $28{ }^{\circ} \mathrm{C}$ durante 2 - 3 horas para Danio rerio (Draper y Moens, 2009); $9{ }^{\circ} \mathrm{C}$ durante 17 días para $O$. mykiss (Ubilla y Valdebenito, 2011); $28{ }^{\circ} \mathrm{C}$ durante 8 h para Colossoma macropomum (Maria et al., 2015); $22{ }^{\circ} \mathrm{C}$ durante 3 h, 3 días y 5 días para Cyprinus carpio (Öğretmen et al., 2015); $26{ }^{\circ} \mathrm{C}$ durante $20 \mathrm{~h}$ para Salminus brasiliensis (Viveiros et al., 2009); $20^{\circ} \mathrm{C}$ durante $4 \mathrm{~h}$ y $60 \mathrm{~h}$ para Misgurnus anguillicaudatus (Yasui et al., 2012); $26{ }^{\circ} \mathrm{C}$ durante $7 \mathrm{~h}$ y 25 h para Piaractus mesopotamicus (Galo et al., 2019).

La relación de seminación juega un papel clave en los ensayos de fertilidad. Por eso, durante la fertilización de los ovocitos de peces, es común usar un exceso de espermatozoides como garantía de la máxima fertilización. Cuando la seminación se realiza con semen crioconservado, la relación semen:ovocitos deben ser aún mayor, dado que la congelación provoca una alta mortalidad de espermatozoides y disminución de la viabilidad celular (Viveiros et al., 2009). Para semen crioconservado se reporta una relación espermatozoides/ovocitos de $3.5 \times 10^{4}$ para Salminus brasiliensis (Weingartner et al., 2015); $1 \times 10^{5}$ para Salvelinus fontinalis, Oncorhynchus mykiss y Cyprinus carpius (Lahnsteiner et al., 2011; Öğretmen et al., 2014; Kutluyer et al., 2015); $1.6 \times 10^{5}$ para Sorubim cuspicaudus (Pardo-Carrasco et al., 2015); $2.5 \times 10^{5}$ para Colossoma macropomum (Maria et al., 2015); $2.7 \times 10^{5}$ para Sal-

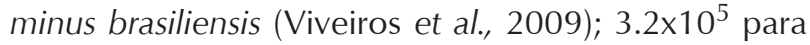
Prochilodus magdalenae (Atencio-García et al., 2015); $2.7 \times 10^{7}$ para Perca flavescens (Miller et al., 2018); $3 \times 10^{5}$ para Salmo trutta y Salvelinus fontinalis (Nynca et al., 2014, 2015b); 5×104 para Thymallus thymallus (Horváth et al., 2015); $5 \times 10^{4}-4 \times 10^{5}$ para Esox lucius (Irena et al., 2020); $5 \times 10^{4}-5 \times 10^{5}$ para Perca fluviatilis (Judycka et al., 2019); $5 \times 10^{5}$ para Hucho hucho (Nyn-

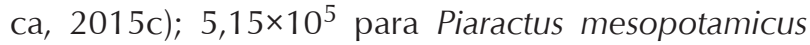

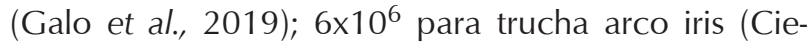
reszko et al., 2014); $7 \times 10^{4}$ para Prochilodus lineatus (Varela-Junior et al., 2015); $7.5 \times 10^{4}$ para Brycon amazonicus (Velasco-Santamaría et al., 2006).

\section{Perspectivas}

La crioconservación seminal en especies nativas dulceacuícolas se ha convertido en una estrategia significativa para abordar los procesos de conservación genética de especies amenazadas o en vía de extin- 
ción, así como una herramienta imprescindible para la producción de alevinos en temporadas asincrónicas de producción de semen. Aun cuando los protocolos deben ser especie específicos, se debe procurar que los investigadores se focalicen en estandarizar metodologías, implementos y variables de medición de calidad espermática que aceleren la producción de paquetes tecnológicos óptimos y totalmente transferibles al sector productivo.

Se hace necesario de igual forma, iniciar o fortalecer iniciativas para la creación de Bancos de Recursos Genéticos para especies ícticas nativas, que estén acompañados de una identificación genética de las especies y una evaluación molecular de los posibles daños celulares causados por la crioconservación para asegurar la calidad de la reserva y transferencia del material genético. Las actividades de producción de semilla a partir del uso de semen crioconservado por parte de los piscicultores pueden servir como base para la identificación de posibles efectos de la biotecnología sobre el desarrollo de la progenie y los futuros reproductores.

La anterior revisión permite establecer una amplia gama de líneas de investigación alrededor de la criobiología espermática en peces dulceacuícolas, ya que aún son muchas las preguntas sin abordar, sin embargo, es gratificante poder concluir que los avances obtenidos alrededor de la crioconservación espermática en peces nativos dulceacuícolas, impulsa la idea de nuevos procesos, productos o servicios a través de la creación de Spin-Off orientados a la comercialización seria, con base científica y responsable del semen crioconservado para uso industrial, tal como ha sucedido en otras especies, como los bovinos.

\section{Agradecimientos}

Los autores agradecen al fondo de Social de Educación Superior de la Gobernación del Meta (FSES) por la beca doctoral del autor Víctor M. Medina-Robles. Asimismo, agradecen al Ministerio de Ciencia, Tecnología e Innovación de Colombia por la beca-pasantía del autor Astrid S. Duarte-Trujillo.

\section{Referencias}

Abed-Elmdoust A, Rahimi R, Farahmand H, Amiri BM, Mirvaghefi A, Rafiee G. Droplet vitrification versus straw cryopreservation for spermatozoa banking in Persian sturgeon (Acipenser persicus) from metabolite point of view. Theriogenology, 2019; 129: 110-115.

Abinawanto A, Wulandari R, Muchlisin ZA. Effect of egg yolk on the spermatozoa quality of the botia Chromobotia macracanthus (Bleeker, 1852) (Cyprinidae) after short-term cryopreservation.
Aquaculture, Aquarium, Conservation \& Legislation, 2018; 11 (6): 1737-1744.

Alavi SMH, Cosson J. Sperm motility in fishes. (II) Effects of ions and osmolality: A review. Cell Biology International, 2006; 30 (1): 1-14.

Alavi SMH, Rodina M, Viveiros ATM, Cosson J, Gela D, Boryshpolets $\mathrm{S}$, Linhart O. Effects of osmolality on sperm morphology, motility and flagellar wave parameters in Northern pike (Esox lucius L.). Theriogenology, 2009; 72 (1): 32-43.

Alquézar-Baeta C, Gimeno-Martos S, Miguel-jiménez S, Santolaria P, Yániz J, Palacín I, Casao A, Cebrián-Pérez JÁ, Muiño-Blanco T, Pérez-Pé R. OpenCASA: A new open-source and scalable tool for sperm quality analysis. PLoS computational biology, 2019; 15 (1): e1006691.

Amann RP, Waberski D. Computer-assisted sperm analysis (CASA): capabilities and potential developments. Theriogenology, 2014; 81 (1): 5-17.e3.

Atencio-García VJ, Espinosa JA, Martínez JG, Pardo-Carrasco SC. Insemination of bocachico fish (Prochilodus magdalenae) with fresh or cryopreserved semen: effect of spermatozoa/oocyte ratio. Revista Colombiana de Ciencias Pecuarias, 2015; 28 (4): 347-355.

Atencio-García V, Longas MD, Petro CM, Pietro-Guevara M, Espinosa-Araujo J. Crioconservación de semen de dorada Brycon moorei con dimetilsulfóxido. Revista Colombiana de Biotecnología, 2017; 19 (2): 81-88.

Aulesa C, Cabrera M, Alonso R, Benítez M, Martínez M. Evaluación del sistema automatizado Sperm Class Analyzer ${ }^{\circledR}$ (SCA) para análisis del semen. Revista del Laboratorio Clínico, 2009; 2 (1): 8-16.

Benson JD. 2015. Modeling and Optimization of Cryopreservation. En: Wolkers WF, Oldenhof H (Editores). Cryopreservation and Freeze-Drying Protocols. Humana Press. Hertfordshire, UK. p. $83-120$.

Bernáth G, Bokor Z, Zarski D, Várkonyi L, Hegyi A, Staszny A, Urbányi B, Radóczi J, Horváth A. Commercial-scale out-of-season cryopreservation of Eurasian perch (Perca fluviatilis) sperm and its application for fertilization. Animal Reproduction Science, 2016; 170: 170-177.

Blom E. A One-Minute Live-Dead Sperm Stain by Means of EosinNigrosin. Fertility and Sterility, 1950; 1 (2): 176-177.

Bobe J, Labbé C. Egg and sperm quality in fish. General and Comparative Endocrinology, 2010; 165 (3): 535-548.

Borges AM, Araújo KO, Pivato I, Navarro RD. Ultraestrutura e criopreservação de sêmen de jundiá amazônico (Leiarius marmoratus) em cativeiro. Arquivo Brasileiro de Medicina Veterinária e Zootecnia, 2020; 72 (1): 253-262.

Boryshpolets S, Dzyuba B, Stejskal V, Linhart O. Dynamics of ATP and movement in Eurasian perch (Perca fluviatilis L.) sperm in conditions of decreasing osmolality. Theriogenology, 2009; 72 (6): 851-859. 
Boryshpolets S, Kholodnyy V, Cosson J, Dzyuba B. Fish sperm motility analysis: the central role of the flagellum. Reproduction, Fertility and Development, 2018; 30 (6): 833-841.

Boryshpolets S, Kowalski RK, Dietrich GJ, Dzyuba B, Ciereszko A. Different computer-assisted sperm analysis (CASA) systems highly influence sperm motility parameters. Theriogenology, 2013; 80 (7): 758-765.

Butts IAE, Ward MAR, Litvak MK, Pitcher TE, Alavi SMH, Trippel EA, Rideout RM. Automated sperm head morphology analyzer for open-source software. Theriogenology, 2011; 76 (9): 17561761.e3.

Cabrita E, Gavaia PJ, Riesco MF, Valcarce DG, Sarasquete C, Herráez MP, Robles V. Factors enhancing fish sperm quality and emerging tools for sperm analysis. Aquaculture, 2014; 432: 389-401.

Cabrita E, Ma S, Diogo P, Martínez-Páramo S, Sarasquete C, Dinis MT. The influence of certain aminoacids and vitamins on postthaw fish sperm motility, viability and DNA fragmentation. Animal Reproduction Science, 2011; 125: 189-195.

Cabrita E, Sarasquete C, Martínez-Páramo S, Robles V, Beirão J, Pérez-Cerezales S, Herráez MP. Cryopreservation of fish sperm: Applications and perspectives. Journal of Applied Ichthyology, 2010; 26 (5): 623-635.

Carneiro PCF, Azevedo HC, Santos JP, Maria AN. Cryopreservation of tambaqui (Colossoma macropomum) semen: Extenders, $\mathrm{Cr}$ yoprotectants, dilution ratios and freezing methods. CryoLetters, 2012; 33 (5): 385-393.

Cartón-garcía F, Riesco MF, Cabrita E, Herráez MP, Robles V. Quantification of lesions in nuclear and mitochondrial genes of Sparus aurata cryopreserved sperm. Aquaculture, 2013; 402-403: 106-112.

Ciereszko A, Dietrich GJ, Nynca J, Dobosz S, Zalewski T. Cryopreservation of rainbow trout semen using a glucose-methanol extender. Aquaculture, 2014; 420-421: 275-281.

Comizzoli P. Advanced biotechnologies for wildlife fertility preservation. Thai Journal of Veterinary Medicine, 2016; 46 (4): 541-545.

Cosson J. Frenetic activation of fish spermatozoa flagella entails short-term motility, portending their precocious decadence. Journal of Fish Biology, 2010; 76 (1): 240-279.

Cruz-Casallas PE, Medina-Robles VM, Velasco-Santamaría YM. Protocolo para la crioconservación de semen de yamú (Brycon amazonicus Spix \& Agassiz 1829). Revista Colombiana de Ciencias Pecuarias, 2006a; 19 (2): 146-151.

Cruz-Casallas PE, Velasco-Santamaría YM, Medina-Robles V. Determinación del espermatocrito y efecto del volumen de la dosis seminante sobre la fertilidad en yamú (Brycon amazonicus). Revista Colombiana de Ciencias Pecuarias, 2006b;19 (2): 140-145.

Ding F, Lall SP, Li J, Lei J, Rommens M, Milley JE. Cryobiology cryopreservation of sperm from Atlantic halibut (Hippoglossus hippoglossus, L.) for commercial application. Cryobiology, 2011; 63 (1): 56-60.
Draper BW, Moens CB. A High-Throughput method for zebrafish sperm cryopreservation and in vitro fertilization. Journal of $\mathrm{Vi}$ sualized Experiments, 2009; (29): e1395.

Dzyuba B, Bondarenko O, Fedorov P, Gazo I, Prokopchuk G, Cosson J. Energetics of fish spermatozoa: The proven and the possible. Aquaculture, 2017; 472: 60-72.

Dzyuba BB, Boryshpolets S, Rodina M, Gela D, Linhart O. Spontaneous activation of spermatozoa motility by routine freezethawing in different fish species. Journal of Applied Ichthyology, 2010; 26 (5): 720-725.

Dzyuba V, Dzyuba B, Cosson J, Boryshpolets S, Yamaner G, Kholodniy $\mathrm{V}$, Rodina $\mathrm{M}$. The antioxidant system of sterlet seminal fluid in testes and Wolffian ducts. Fish Physiology and Biochemistry, 2014; 40 (6): 1731-1739.

Dzyuba V, Dzyuba B, Cosson J, Rodina M. Enzyme activity in energy supply of spermatozoon motility in two taxonomically distant fish species (sterlet Acipenser ruthenus, Acipenseriformes and common carp Cyprinus carpio, Cypriniformes). Theriogenology, 2016; 85 (4): 567-574.

Engel KM, Grunewald S, Schiller J, Paasch U. Automated semen analysis by SQA Vision ${ }^{\circledR}$ versus the manual approach $-A$ prospective double-blind study. Andrologia, 2019; 51 (1): e13149.

Evenson DP. 2018. Sperm Chromatin Structure Assay (SCSA®): Evolution from Origin to Clinical Utility. En: Zini A, Agarwal A (Editores). A Clinician's Guide to Sperm DNA and Chromatin Damage. Springer International Publishing. Montreal, Canada y Cleveland, USA. p. 65 - 90.

FAO - Organización de las Naciones Unidas para la Alimentación y la Agricultura. Visión general del sector acuícola nacional: Colombia; [Fecha de acceso: septiembre 2 de 2019] URL: http://www.fao.org/fishery/countrysector/naso_colombia/ es\#tcN900B1

Faustino F, Silva RCD, Hilbig CC, Makino LC, Senhorini JA, NinhausSilveira A, Nakaghi LSO. Spermatozoon ultrastructure and semen parameters of Brycon vermelha (Characiformes, Characidae). Animal Reproduction Science, 2015; 157: 17-23.

Fauvel BC, Suquet $M$, Cosson J. Evaluation of fish sperm quality. Journal of Applied Ichthyology, 2010; 26 (5): 636-643.

Fernandes MDO, Sergio A, Junior V, Acosta IB, Mari S, Gheller M, Corcini CD. Cryopreservation of sperm in annual fish Austrolebias minuano (Cyprinodontiformes; Rivulidae). Aquaculture Research, 2019; 51 (1): 147-154.

Fernández A, Gonzalvo M del C, Clavero A, Ruíz de Assín R, Zamora S, Roldán M, Rabelo B, Ramírez JP, Yoldi A, Castilla JA. Fundamentos de criobiología espermática para bancos de semen. Revista ASEBIR, 2009; 14 (1): 17-25.

Figueroa E, Lee-estevez M, Valdebenito I, Watanabe I, Oliveira RPS, Romero J. Effects of cryopreservation on mitochondrial function and sperm quality in fish. Aquaculture, 2019; 511: 634190.

Figueroa E, Valdebenito I, Farias JG. Technologies used in the study of sperm function in cryopreserved fish spermatozoa. Aquaculture Research, 2016; 47 (6): 1691-1705. 
Figueroa E, Valdebenito I, Zepeda AB, Figueroa CA, Dumorné K, Castillo RL, Farias JG. Effects of cryopreservation on mitochondria of fish spermatozoa. Reviews in Aquaculture, 2017; 9 (1): 76-87.

Fitzpatrick JL, Garcia-gonzalez F, Evans JP. Linking sperm length and velocity: the importance of intramale variation. Biology Letters, 2010; 6 (6): 797-799.

Freyhof J, Brooks E (Editores). 2011. European Red List of Freshwater Fishes. Office of the European Union, Luxembourg, p. 70.

Gallego V, Pérez L, Asturiano JF, Yoshida M. Relationship between spermatozoa motility parameters, sperm/egg ratio, and fertilization and hatching rates in puffer fish (Takifugu niphobles). Aquaculture, 2013; 416-417: 238-243.

Galo JM, Streit-Junior DP, Oliveira CA, Povh JP, Fornari DC, Digmayer M, Ribeiro RP. Quality of fresh and cryopreserved semen and their influence on the rates of fertilization, hatching and quality of the larvae of Piaractus mesopotamicus. Brazilian Journal of Biology, 2019; 79 (3): 438-445.

Giaretta E, Munerato M, Yeste M, Galeati G, Spinaci M, Tamanini C, Mari G, Bucci D. Implementing an open-access CASA software for the assessment of stallion sperm motility: Relationship with other sperm quality parameters. Animal Reproduction Science, 2017; 176: 11-19.

Gillies EA, Bondarenko V, Cosson J, Pacey AA. Fins improve the swimming performance of fish sperm: a hydrodynamic analysis of the Siberian sturgeon Acipenser baerii. Cytoskeleton, 2013; 70(2): 85-100

Gray J, Hancock GJ. The propulsion of sea-urchin spermatozoa. Journal of Experimental Biology, 1955; 32 (4): 802-814.

Grevle I, Ruud K. 2019. Cryopreservation device for biological material. Patente no. US 2019/0166826 A1, Clasificación A01N1 / 0242, p. 4.

Gunes S, Sertyel S. 2018. Sperm DNA Damage and Oocyte Repair Capability. En: Zini A, Agarwal A (Editores). A Clinician's Guide to Sperm DNA and Chromatin Damage. Springer International Publishing. Montreal, Canada y Cleveland, USA. p. 325-350.

Guo W, Shao J, Li P, Wu J, Wei Q. Morphology and ultrastructure of Brachymystax lenok tsinlingensis spermatozoa by scanning and transmission electron microscopy. Tissue and Cell, 2016; 48 (4): 321-327.

Herrera-Cruz E, Aristizabal-Regino J, Yepes-Blandón J, Estrada-Posada A, Espinosa-Araujo J, Atencio-Garcia V. Criopreservación de semen de bagre rayado Pseudoplatystoma magdaleniatum con tres diferentes crioprotectores. Revista Colombiana de Biotecnología, 2019; 21 (2): 55-62.

Horváth Á, Bokor Z, Bernáth G, Csenki Z, Gorjan A, Paz M, Urbányi B. Very low sperm - egg ratios result in successful fertilization using cryopreserved sperm in the Adriatic grayling (Thymallus thymallus). Aquaculture, 2015; 435: 75-77.

ICA - Instituto Colombiano Agropecuario. Protección sanitaria de las especies acuícolas [Fecha de acceso: septiembre 2 de 2019] URL: https://www.ica.gov.co/getdoc/b082c759-18c7-47dabed6-0ebe76b48fe0/acuicolas-(1).aspx
İnanan BE, Yilmaz F. Motility evaluation and cryopreservation of fish sperm exposed by water-borne and food-borne boron. Journal of Aquaculture Engineering and Fisheries Research, 2018; 4 (1):12-19.

Inkson BJ. 2016. Scanning electron microscopy (SEM) and transmission electron microscopy (TEM) for materials characterization. En: Hübschen G, Altpeter I, Tschuncky R, Herrmann HG (Editores). Materials characterization using nondestructive evaluation (NDE) methods. Woodhead Publishing. Duxford, UK, Cambridge, USA y Kidlington, UK. p. 17-43.

Irena B, Sarosiek B, Dryl K, Judycka S, Szczepkowska B. The effect of cryopreservation extender on sperm motility and hatch success in northern pike (Esox lucius). Aquaculture, 2020; 514: 734482.

Isachenko V, Sánchez R, Rahimi G, Mallmann P, Isachenko E, Merzenich M. Cryoprotectant-free vitrification of spermatozoa: fish as a model of human. Andrologia, 2018; 51 (1): e13166.

Judycka S, Żarski D, Dietrich MA, Palińska-Żarska K, Karol H, Ciereszko A. Standardized cryopreservation protocol of European perch (Perca fluviatilis) semen allows to obtain high fertilization rates with the use of frozen/thawed semen. Aquaculture, 2019; 498: 208-216.

Kahwa D, Nyatia E, Rutaisire J, Kaiser H. Spermatozoa morphology and ultrastructure in Nile perch, Lates niloticus (Linnaeus, 1758). African Journal of Aquatic Science, 2019; 44 (1): 97-102.

Kashou AH, Sharma R, Agarwal A. 2012. Assessment of Oxidative Stress in Sperm and Semen. En: Carrell DT, Aston KI (Editores). Spermatogenesis. Humana Press. New York, USA. p. 351-361.

Kopeika E, Kopeika J, Zhang T. 2007. Cryopreservation of fish sperm. En: Day JG, Stacy G (Editores). Cryopreservation and FreezeDrying Protocols. Human Press. Totowa, USA. p. 203-217.

Kutluyer F, Kayim M, Öğretmen F, Büyükleblebici S, Tuncer PB. Cryopreservation of rainbow trout Oncorhynchus mykiss spermatozoa: Effects of extender supplemented with different antioxidants on sperm motility, velocity and fertility. Cryobiology, 2014; 69(3): 462-466.

Lahnsteiner F, Mansour N, Kunz FA. The effect of antioxidants on the quality of cryopreserved semen in two salmonid fish, the brook trout (Salvelinus fontinalis) and the rainbow trout (Oncorhynchus mykiss). Theriogenology, 2011; 76 (5): 882-890.

Lahnsteiner F, Mansour N, Plaetzer K. Antioxidant systems of brown trout (Salmo trutta f. fario) semen. Animal Reproduction Science, 2010; 119 (3-4): 314-321.

Li P, Guo W, Qiao XM, Liu ZG, Shen L, Wei QW. Morphology and ultrastructure of Dabry's sturgeon (Acipenser dabryanus) spermatozoa using scanning and transmission electron microscopy. Journal of Applied Ichthyology, 2019; 35 (1): 192-201.

Li P, Hulak M, Koubek P, Sulc M, Dzyuba B, Boryshpolets S, Rodina M, Gela D, Manaskova-Postlerova P, Peknicova J, Linhart O. Ice-age endurance: The effects of cryopreservation on proteins of sperm of common carp, Cyprinus carpio L. Theriogenology, 2010; 74 (3): 413-423.

Li P, Hulak M, Li ZH, Sulc M, Psenicka M, Rodina M, Gela D, Linhart O. Cryopreservation of common carp (Cyprinus carpio L.) 
sperm induces protein phosphorylation in tyrosine and threonine residues. Theriogenology, 2013; 80 (2): 84-89.

López-Hernández JC, Osorio-Pérez A, Jiménez-Félix AS, PáramoDelgadillo S, Márquez-Couturier G, Yasui GS, Arias-Rodríguez L. La calidad espermática en peces y los métodos de evaluación. Revista Ciencias Marinas y Costeras, 2018; 10 (1): 67-96.

Maria AN, Azevedo HC, Santos JP, Silva CA, Carneiro PCF. Semen characterization and sperm structure of the Amazon tambaqui Colossoma macropomum. Journal of Applied Ichthyology, 2010; 26 (5): 779-783.

Maria AN, Carvalho ACM, Araújo RV, Santos JP, Carneiro PCF, Azevedo HC. Use of cryotubes for the cryopreservation of tambaqui fish semen (Colossoma macropomum). Cryobiology, 2015; 70 (2): 109-114.

Martínez JG, Atencio-García V, Pardo-Carrasco S. DNA fragmentation and membrane damage of bocachico Prochilodus magdalenae (Ostariophysi: Prochilodontidae) sperm following cryopreservation with dimethylsulfoxide and glucose. Neotropical Ichthyology, 2012; 10 (3): 577-586.

Martínez JG, Pardo S. Effect of freezing and thawing rates on sperm motility in bocachico Prochilodus magdalenae (pisces, characiformes). Revista MVZ Cordoba, 2013; 18 (1): 3295-3303.

Martínez-páramo S, Diogo P, Dinis MT, Herráez MP, Sarasquete C. Incorporation of ascorbic acid and $\alpha$-tocopherol to the extender media to enhance antioxidant system of cryopreserved sea bass sperm. Theriogenology, 2012; 77 (6): 1129-1136.

Martínez-Páramo S, Horváth Á, Labbé C, Zhang T, Robles V, Herráez $\mathrm{P}$, Suquet $\mathrm{M}$, Adams $\mathrm{S}$, Viveiros $\mathrm{A}$, Tiersch TR, Cabrita E. Cryobanking of aquatic species. Aquaculture, 2017; 472: 156177.

Mazur P. Kinetics of Water Loss from Cells at Subzero Temperatures and the Likelihood of Intracellular Freezing. The Journal of General Physiology, 1963; 47 (2): 347-369.

Mazur P, Leibo SP, Chu EHY. A Two-Factor Hypothesis of Freezing Injury: Evidence from Chinese Hamster Tissue-culture Cells. Experimental Cell Research, 1972; 71 (2): 345-355.

Medina-Robles VM, Guaje-Ramírez DN, Marin-Cossio LC, Sandoval-Vargas LY, Cruz-Casallas PE. Crioconservación seminal de Colossoma macropomum como estrategia de producción y conservación en la Orinoquia Colombiana. Revista Orinoquia, 2019; 23 (1): 15-24.

Medina-Robles VM, Velasco-Santamaría YM, Cruz-Casallas PE. Los bancos de recursos genéticos y su papel en la conservación de la biodiversidad. Revista Orinoquia, 2006; 10 (1): 71-77.

Medina-Robles VM, Velasco-Santamaría YM, Cruz-Casallas PE. Efecto del volumen de empaque sobre la tasa de congelación- descongelación y la fertilidad de semen crioconservado de yamú (Brycon amazonicus). Archivos de Medicina Veterinaria, 2007; 39 (3): 229-237.

Melo-Maciel MAP, Nunes JF, Pinheiro JPS, Nunes LT, Pinheiro RRR, Lopes JT, Salmito-Vanderley CSB. Sperm motility and velocities of Characiformes fishes in different times post-activation. Semina: Ciências Agrárias, 2015; 36 (6): 4023-4030.
Cunha ATM, Carvalho JDO, Dode MAN. Techniques for sperm evaluation using fluorescent probes. Embrapa Recursos Genéticos e Biotecnologia, 2015; 36 (6): 4365-4376.

Miliorini AB, Murgas LDS, Rosa PV, Oberlender G, Pereira GJM, Da Costa DV. A morphological classification proposal for curimba (Prochilodus lineatus) sperm damages after cryopreservation. Aquaculture Research, 2011; 42 (2): 177-187.

Miller ME, Kemski M, Grayson JD, Towne K, Dabrowski K. Yellow Perch sperm motility, cryopreservation, and viability of resulting larvae and juveniles. North American Journal of Aquaculture, 2018; 80 (1): 3-12.

Mojica JI, Usma JS, Álvarez-León R, Lasso CA (Editores). 2012. Libro rojo de peces dulceacuícolas de Colombia. Instituto de Investigación de Recursos Biológicos Alexander von Humboldt, Instituto de Ciencias Naturales de la Universidad Nacional de Colombia, WWF Colombia y Universidad de Manizales. Bogotá, p. 164.

Molnár J, Bokor Z, Várkonyi L, Izsák T, Füzes-Solymosi E, Láng ZL, Csorbai B, Tarnai-Király ZS, Urbányi B, Bernáth G. The systematic development and optimization of large-scale sperm cryopreservation in northern pike (Esox lucius). Cryobiology, 2020; 94: 26-31.

Morales AM, Álvarez OG, Ramón M, Pastor FM, Santos MRF, Soler AJ, Garde JJ. Current status and potential of morphometric sperm analysis. Asian Journal of Andrology, 2016; 18 (6): 863870.

Muchlisin ZA, Sarah PI, Aldila DF, Eriani K, Hasri I, Batubara AS, Nur FM, Mustagim M, Muthmainnah CR, Abinawanto A, Wilkes M. Effect of Dimethyl sulfoxide (DMSO) and egg yolk on sperm motility, fertility and hatching rates of depik Rasbora tawarensis (Pisces: Cyprinidae) eggs after short-term cryopreservation. Aquaculture Research, 2020; 51 (4): 1700-1705.

Murgas LDS, Paulino MS, Palhares PC, Miliorini AB, Alves E, Felizardo VDO. Ultrastructural and morphometric analysis of gametes in neotropical teleost fishes. Journal of FisheriesSciences.com, 2017; 11 (1): 56-61.

Nynca J, Arnold GJ, Fröhlich T, Ciereszko A. Cryopreservation-induced alterations in protein composition of rainbow trout semen. Proteomics, 2015a; 15 (15): 2643-2654.

Nynca J, Dietrich GJ, Dobosz S, Grudniewska J, Ciereszko A. Effect of cryopreservation on sperm motility parameters and fertilizing ability of brown trout semen. Aquaculture, 2014; 433: 62-65.

Nynca J, Dietrich GJ, Dobosz S, Zalewski T, Ciereszko A. Effect of postthaw storage time and sperm-to-egg ratio on fertility of cryopreserved brook trout sperm. Theriogenology, 2015b; 83 (2): 253-256.

Nynca J, Dietrich GJ, Grudniewska J, Dobosz S, Liszewska E, Krzy M, Ciereszko A. Efficient method for cryopreservation of European huchen (Hucho hucho L.) and grayling (Thymallus thymallus L.) semen. Aquaculture, 2015c; 435: 146-151.

OCDE - Organización para la Cooperación y el Desarrollo Económicos. 2016. Pesca y acuicultura en Colombia. Bogotá, Colombia.

Öğretmen F, Inanan BE. Effect of butylated hydroxytoluene (BHT) on the cryopreservation of common carp (Cyprinus carpio) 
spermatozoa. Animal Reproduction Science, 2014a; 151(3-4): 269-274.

Öğretmen F, Inanan BE. Evaluation of the cryoprotective effect of turkish pine honey on common carp (Cyprinus carpio) spermatozoa. CryoLetters, 2014b; 53 (5): 427-437.

Öğretmen F, Inanan BE, Kutluyer F, Kayim M. Effect of semen extender supplementation with cysteine on postthaw sperm quality, DNA damage, and fertilizing ability in the common carp (Cyprinus carpio). Theriogenology, 2015; 83 (9): 1548-1552.

Öğretmen F, Inanan BE, Öztürk M. Protective effects of propolis on cryopreservation of common carp (Cyprinus carpio) sperm. Cryobiology, 2014; 68 (1): 107-112.

Pardo-Carrasco SC, Salas-Villalva J, Reza-Gaviria L, Espinosa-Araujo J, Atencio-García V. Criopreservación de semen de Bagre blanco (Sorubim cuspicaudus) condimetilacetamida como crioprotector. CES Medicina Veterinaria y Zootecnia, 2015; 10 (2): 122131.

Partyka A, Niżański W, Ochota M. 2012. Methods of assessment of cryopreserved semen. En: Katkov II (Editor). Current Frontiers in Cryobiology. InTech. Rijeka, Croatia. p. 547-574.

Pegg DE. 2007. Principles of cryopreservation. En: Day JG, Stacy G (Editores). Cryopreservation and Freeze-Drying Protocols. Human Press. Totowa, USA. p. 39-57.

Pegg DE. 2015. Principles of Cryopreservation. En: Wolkers WF, OIdenhof H (Editores). Cryopreservation and Freeze-Drying Protocols. Humana Press. Hertfordshire, UK. p. 3-20.

Pérez-Cerezales S, Martínez-Páramo S, Beirão J, Herráez MP. Evaluation of DNA damage as a quality marker for rainbow trout sperm cryopreservation and use of LDL as cryoprotectant. Theriogenology, 2010; 74 (2): 282-289.

Pinheiro JPS, Melo-Maciel MAP, Linhares FRA, Lopes JT, AlmeidaMonteiro PS, Pinheiro RRR, Torres TM, Salmito-Vanderley C. Use of glucose or BTS TM combined with DMSO or methylglycol under two different freezing protocols for the cryopreservation of sperm from the common curimatã (Prochilodus brevis). Animal Reproduction, 2016; 13 (4): 779-786.

Prieto-Mojica CA, Moreno-Nuñez PA, Vicentini CA. Ultraestructura de la espermiogénesis y de los espermatozoides de Gymnocorymbus ternetzi, Hyphessobrycon bifasciatus y de Hyphessobry eques. Revista Colombiana de Ciencias Pecuarias, 2008; 21: 455

Purdy PH, Graham JK. 2015. Membrane Modification Strategies for Cryopreservation. En: Wolkers WF, Oldenhof H (Editores). Cryopreservation and Freeze-Drying Protocols. Humana Press. Hertfordshire, UK. p. 352-357.

Rajasekharan PE. 2017. Conservation of Bioresources. En: Abdulhameed S, Pradeepy NS, Sugathan S (Editores). Bioresources and Bioprocess in Biotechnology. Springer Nature, Singapore. p. 25-47.

Ramalho-Santos J, Amaral A, Sousa AP, Rodrigues AS, Martins L, Baptista M, Mota PC, Tavares R, Amaral S, Gamboa S. Probing the Structure and Function of Mammalian Sperm using Optical and Fluorescence Microscopy. Modern Research and Educational Topics in Microscopy, 2007; 1: 394-402.
Reis RE, Albert JS, Di Dario F, Mincarone MM, Petry P, Rocha LA. Fish biodiversity and conservation in South America. Journal of Fish Biology, 2016; 89 (1): 12-47.

Rodao M, Montagne J, Clivio A, Papa GN, Casanova LG. 2016. Sperm and egg envelope ultrastructure and some considerations on its evolutionary meaning. En: Berois N, García G, De Sá RO (Editores). Annual fishes: Life History Strategy, Diversity and Evolution. CRC Press. Boca Ratón, USA. p. 47-61.

Rodríguez-martínez H. Semen evaluation: can we forecast fertility? Veterinarska Stanica, 2019; 50 (4): 293-305.

Shaliutina-Kolešová A, Cosson J, Lebeda I, Gazo I, Shaliutina $O$, Dzyuba B, Linhart O. The influence of cryoprotectants on sturgeon (Acipenser ruthenus) sperm quality, DNA integrity, antioxidant responses, and resistance to oxidative stress. Animal Reproduction Science, 2015; 159: 66-76.

Sharma R, Masaki J, Agarwal A. 2013. Sperm DNA fragmentation analysis using the TUNEL assay. En: Carrell D, Aston K (Editores). Spermatogenesis. Humana Press. Totowa, USA. p. 121 $-136$.

Smith KG, Barrios V, Darwallet WRT, Numa C (Editores). 2014. The status and distribution of freshwater biodiversity in the eastern Mediterranean. International Union for Conservation of Nature (IUCN), Cambridge, Malaga and Gland, p. 149.

Takei GL, Mukai C, Okuno M. Transient Ca2+ mobilization caused by osmotic shock initiates salmonid fish sperm motility. Journal of Experimental Biology, 2012; 215 (4): 630-641.

Tan E, Yang H, Tiersch TR. Determination of Sperm Concentration for Small-Bodied Biomedical Model Fishes by Use of Microspectrophotometry. Zebrafish, 2010; 7 (2): 233-240.

Tedesco PA, Beauchard O, Bigorne R, Blanchet S, Buisson L, Conti L, Cornu JF, Dias MS, Grenouillet G, Hugueny B, Jézéquel C, Leprieur F, Brosse S, Oberdorff T. Data Descriptor: A global database on freshwater fish species occurrence in drainage basins. Scientific Data, 2017; 4: 170141.

Tiersch TR. Strategies for commercialization of cryopreserved fish semen. Revista Brasileira de Zootecnia, 2008; 37 (suplemento): 15-19.

Ubilla A, Valdebenito I. Use of antioxidants on rainbow trout Oncorhynchus mykiss (Walbaum, 1792) sperm diluent: effects on motility and fertilizing capability. Latin American Journal of Aquatic Research, 2011; 39 (2): 338-343.

Varela-Junior AS, Fernandes-Silva E, Figueiredo-Cardoso T, Yokoyama-Namba É, Desessards-Jardim R, Streit-Junior DP, Dahl-Corcini $\mathrm{C}$. The role of dimethyl sulfoxide in the cryopreservation of Curimba (Prochilodus lineatus) semen. Semina: Ciências Agrárias, $2015 ; 36$ (5): 3471-3479.

Varela-Junior AS, Goularte KL, Alves JP, Pereira FA, Silva EF, Cardoso TF, Jardim RD, Streit-Junior DP, Corcini CD. Methods of cryopreservation of Tambaqui semen, Colossoma macropomum. Animal Reproduction Science, 2015; 157: 71-77.

Várkonyi L, Bokor Z, Molnár J, Fodor F, Szári Z, Ferincz Á, Staszny Á, Láng LZ, Csorbai B, Urbányi B, Bernáth G. The comparison of two different extenders for the improvement of large-scale 
sperm cryopreservation in common carp (Cyprinus carpio). Reproduction in Domestical Animals, 2019; 54 (3): 639-645.

Velasco-Santamaría YM, Medina-Robles VM, Cruz-Casallas PE. Cryopreservation of yamú (Brycon amazonicus) sperm for large scale fertilization. Aquaculture, 2006; 256 (1-4): 264-271.

Viveiros ATM, Godinho HP. Sperm quality and cryopreservation of Brazilian freshwater fish species: A review. Fish Physiology and Biochemistry, 2009; 35 (1): 137-150.

Viveiros AT, Maria AN, Amaral TB, Orfão LH, Isau ZA, Veríssimo-Silveira R. Spermatozoon ultrastructure and sperm cryopreservation of the Brazilian dry season spawner fish pirapitinga, Brycon nattereri. Aquaculture Research, 2012; 43 (4): 546-555.

Viveiros ATM, Nascimento AF, Orfão LH, Isaú ZA. Motility and fertility of the subtropical freshwater fish streaked prochilod (Prochilodus lineatus) sperm cryopreserved in powdered coconut water. Theriogenology, 2010; 74 (4): 551-556.

Viveiros ATM, Oliveira A V, Maria AN, Orfão LH, Souza JC. Sensibilidade dos espermatozoides de dourado (Salminus brasiliensis) a diferentes soluções crioprotetoras. Arquivo Brasileiro de Medicina Veterinaria e Zootecnia, 2009; 61 (4): 883-889.

Volpedo A, Thompson GA. Environmental changes on freshwater fish communities in South America in the last five decades: a case study in northeast Argentina. Sustainability, Agri, Food and Environmental Research, 2017; 4 (3): 47-61.

Watson PF, Fuller BJ. 2001. Principles of Cryopreservation Gametes and Embryos. En: Watson PF, Holt WV (Editores). Cryobanking the Genetic Resource: Wildlife Conservation for the Future? Taylor \& Francis. London, UK. p. 21-46.
Weingartner M, Zanandrea ACV, Zaniboni-Filho E. Cryopreserved sperm for oocyte fertilization of dourado Salminus brasiliensis. Ciência Rural, 2015; 45 (5): 892-897.

Wilson-leedy JG, Ingermann RL. Development of a novel CASA system based on open source software for characterization of zebrafish sperm motility parameters. Theriogenology, 2007; 67: 661-672.

Woelders H, Chaveiro A. Theoretical prediction of "optimal" freezing programmes. Cryobiology, 2004; 49 (3): 258-271.

WWF - World Wildlife Fund. 2018. Living planet report - 2018: Aiming Higher. Gland, Switzerland.

Yang H, Tiersch TR. Comparative Biochemistry and Physiology, Part C Current status of sperm cryopreservation in biomedical research fish models: Zebra fish, medaka, and Xiphophorus. Comparative Biochemistry and Physiology Part C: Toxicology \& Pharmacology, 2009; 149 (2): 224-232.

Yang S, Zhang X, Liu X, Hu J, Wang Y, Du Z, Yan T. Chorion surface ultrastructure of loach Misgurnus anguillicaudatus: adaptation to the environment and correlation with the reproductive strategy. Journal of Natural History, 2014; 48(35-36): 2207-2218.

Yasui GS, Fujimoto T, Arias-rodriguez L, Takagi Y, Arai K. The effect of ions and cryoprotectants upon sperm motility and fertilization success in the loach Misgurnus anguillicaudatus. Aquaculture, 2012; 344-349: 147-152.

Yildiz C, Yavas I, Bozkurt Y, Aksoy M. Cryobiology Effect of cholesterol-loaded cyclodextrin on cryosurvival and fertility of cryopreserved carp (Cyprinus carpio) sperm. Criobiology, 2015; 70 (2): 190-194. 